Revista Brasileira de Informática na Educação - RBIE Brazilian Journal of Computers in Education (ISSN online: 2317-6121; print: 1414-5685)

http://br-ie.org/pub/index.php/rbie

\begin{tabular}{llll}
\hline Submission: $01 / 07 / 2020 ;$ & $1^{\text {st }}$ round notif:: $13 / 09 / 2020 ;$ & New version: 01/10/2020; & $2^{\text {nd }}$ round notif.: $12 / 11 / 2020 ;$ \\
Camera ready: $14 / 12 / 2020 ;$ & Edition review: $10 / 01 / 2021 ;$ & Available online: 22/01/2021; & Published: 22/01/2021;
\end{tabular}

\title{
Uma Análise do Perfil dos Cursos de Licenciatura em Computação no Brasil
}

\section{Title: An Analysis of Computer Science Teacher Education Courses in Brazil}

\author{
André Menolli \\ Centro de Ciências Tecnológicas \\ Universidade Estadual do Norte do Paraná -UENP \\ Campus de Bandeirantes \\ Programa de Pós-Graduação em Ciência da \\ Computação \\ Universidade Estadual de Londrina - UEL \\ menolli@uenp.edu.br
}

\author{
João Coelho Neto \\ Centro de Ciências Humanas e da Educação \\ Programa de Pós-Graduação em Ensino \\ Universidade Estadual do Norte do Paraná -UENP \\ Campus de Cornélio Procópio \\ joaocoelho@uenp.edu.br
}

\begin{abstract}
Resumo
O pensamento computacional vem ganhando importância na educação básica, como instrumento para o desenvolvimento da aprendizagem, e os cursos de licenciatura em computação são responsáveis pela formação de profissionais capacitados para fomentá-lo. Desse modo, o objetivo dessa pesquisa é mapear os cursos de licenciatura em computação no Brasil, a fim de apresentar um panorama referente ao perfil destes cursos e identificar fatores associados à taxa de evasão. Para o método de pesquisa, utilizou-se o design science research, sendo definido e implantado um método para análise de dados públicos baseado em business intelligence. Após o método ter sido implantado, dados das instituições do ensino superior no Brasil foram analisados, sendo explorado o perfil dos cursos e alunos de licenciatura em computação, em especial o fenômeno da evasão. Os resultados mostram diferenças nas taxas de evasão em relação à etnia, tipo de cidade onde o curso está localizado, tipo de instituição, modalidade de ensino, ano de ingresso no curso e período do curso. Resultados preocupantes com relação à taxa de evasão e número de ingressantes em anos recentes em cursos de licenciatura em computação foram, também, identificados.
\end{abstract}

Palavras-Chave: Business Intelligence; Licenciatura em Computação; Análise de Dados

\begin{abstract}
Computational thinking has been gaining importance in basic education, as an instrument for the development of learning, and the computer courses, focusing on training teachers (Computer Science Teacher Education) are responsible for training professionals to foster it. Thus, the goal of this research is to map the computer lecturing courses and identify associated factors to dropout. As a research method, it was used the design science research. A method for analyzing public data, based on business intelligence, was defined and deployed. So, data from higher education institutions in Brazil were analyzed, exploring the profile of courses and students in computer lecturing courses, with special emphasis on the dropout phenomenon. The results show differences in dropout rates in relation to ethnicity, type of city where the course is located, type of institution, type of education, year of entry into the course, and the period of the course. It also presents worrying results regarding the dropout rate and the number of students enrolled in the computer lecturing courses in the last years.
\end{abstract}

Keywords: Business Intelligence; Computer Lecturing Courses; Data Analysis.

Cite as: Menolli, A. \& Coelho Neto, J. (2021). An Analysis of Computer Science Teacher Education Courses in Brazil (Uma Análise do Perfil dos Cursos de Licenciatura em Computação no Brasil). Brazilian Journal of Computers in Education (Revista Brasileira de Informática na Educação - RBIE), 29, 01-24. DOI: 10.5753/RBIE.2021.29.0.01 


\section{Introdução}

A informática na educação é um meio de contextualizar ferramentas para serem integradas em diversos contextos de ensino. Corroborando nesse aspecto, Valente (1999a, p. 1) ressalta que "o termo informática na educação [...] refere-se à inserção do computador no processo de ensinoaprendizagem de conteúdos curriculares de todos os níveis e modalidades de educação".

Diante dessa perspectiva, o mesmo autor retrata que o computador "[...] pode ser um importante recurso para promover a passagem da informação ao usuário ou facilitar o processo de construção de conhecimento" (Valente, 1999b, p. 90).

Atualmente, o ensino de computação, principalmente na educação básica, vem ganhando importância, uma vez que a introdução do pensamento computacional e algorítmico nesse nível de ensino pode vir a fornecer os recursos cognitivos necessários para a resolução de problemas, transversal a todas as áreas do conhecimento (Brasil, 2016).

A crescente importância do pensamento computacional no ensino pode ser percebida pelas diversas referências a ele na Base Nacional Comum Curricular (BNCC) do Brasil (Brasil, 2018). $\mathrm{Na} \mathrm{BNCC}$, a articulação do pensamento computacional com as competências gerais é comtemplada nos objetivos de aprendizagem e desenvolvimento da Educação Infantil e nas competências específicas e habilidades dos diferentes componentes curriculares do Ensino Fundamental.

Diante deste panorama, muitas escolas adotam iniciativas para fortalecerem o pensamento computacional, como aulas de robótica educacional, clubes de programação, criação de jogos digitais, simuladores e atividades interdisciplinares com "computação desplugada" (Bell, Witten, e Fellows, 2011). A adoção de recursos para a educação assistida por computador e os sistemas de Educação a Distância visam, principalmente, tornar a interação para o ensino e a aprendizagem mais prazerosa, autônoma e efetiva por meio da introdução de princípios e conceitos pedagógicos na interação humano-computador.

Baranauskas, Rocha, Martins e D’Abreu (1999, p. 50) ressaltam que o ensino assistido ou auxiliado por computador "[...] parte do pressuposto de que a informação é a unidade fundamental no ensino e, portanto, preocupa-se com os processos de como adquirir, armazenar, representar e principalmente, transmitir informação. Nesse sentido, o computador é visto como uma ferramenta poderosa de armazenamento, representação e transmissão da informação".

Conceitualmente, todos os sistemas computacionais com funcionalidade pedagógica ou que necessita de assistência para seu uso requer a participação dos licenciados em computação (Brasil, 2016). Contudo, na prática a realidade é diferente. Muitas escolas utilizam a aplicação de funcionalidades pedagógicas por meio de sistemas computacionais sem contratar um profissional adequado. Assim, tem-se profissionais capacitados para realizar estas atividades e que muitas vezes não são absorvidos nas funções para as quais foram preparados e, por outro lado, há escolas adotando sistemas computacionais com funcionalidades pedagógicas sem a supervisão de um profissional capacitado para auxiliar nesta tarefa.

Considerando essa tendência na aplicação de pensamento computacional e das TDIC (Tecnologias Digitais de Informação e Comunicação) em estágios iniciais do ensino, os cursos de licenciatura em computação deveriam estar em próspera ascensão, uma vez que formam profissionais capacitados para fomentar o pensamento computacional junto aos alunos nos diversos eixos de formação do ensino.

Dessa maneira, é importante entender os dados sobre os cursos de licenciatura em computação no Brasil, tais como o local em que ocorrem, características das instituições, cursos e alunos. Além disso, é necessário entender os dados sobre evasão nestes cursos e compará-los a outros cursos, em especial aos da área de computação. 
A evasão no sistema de ensino superior é um processo complexo e um fenômeno comum em instituições de ensino superior privadas e públicas. Por esta razão, é um tema abordado em vários trabalhos ao longo dos últimos anos por autores como Fritsch, Rocha e Vitelli (2015); Rodrigues, Brackmann e Barone (2015); Damasceno e Carneiro (2018); Brito, Medeiros, Bezerra e Barbosa, (2020).

As causas deste fenômeno têm muitas rotas e consequências. Apenas para citar algumas, a alta expectativa sobre os cursos (Berardi e Bim, 2017) ou mesmo uma compreensão conflitante da área (Silva Filho, Hipólito e Lobo, 2007). Especificamente na área de licenciatura em computação, alguns autores, em seus trabalhos, exploram o fenômeno da evasão, tais como Prietche e Pazeto (2010). Contudo, estes estudos abordam instituições específicas e não um entendimento geral sobre como esse fenômeno ocorre em cursos similares no Brasil.

Assim sendo, há uma necessidade contínua de analisar esse fenômeno para um nível mais amplo (por exemplo, Nível Nacional - Brasil), além de entender o perfil de alunos e cursos de licenciatura em computação, para, a partir destes dados, entender o impacto geral das políticas públicas e dos esforços existentes.

Dessa maneira, este artigo apresenta uma ampla análise sobre os dados dos cursos superiores em licenciatura em computação. O objetivo é mapear os cursos de Licenciatura em Computação no Brasil, a fim de identificar um panorama referente ao seu perfil e identificar fatores associados à taxa de evasão ${ }^{1}$ destes cursos. Para atingir o objetivo geral, propomos responder às seguintes questões de pesquisa:

a) É possível, por meio de dados públicos, conseguir um panorama dos cursos de licenciatura em computação?

b) Quais fatores estão associados à taxa de evasão destes cursos?

Para atingir o objetivo do trabalho, utilizamos dados públicos dos anos de 2017 e 2018 do INEP (Instituto Nacional de Educação Anísio Teixeira Estudos e Pesquisas). A partir dos dados, para realizar as análises utilizamos diversas técnicas computacionais, como transformação, limpeza e integração de dados, modelagem dimensional e DW (Data Warehouse), além de ferramentas de inteligência de negócios ou BI (Business Intelligence).

Vale destacar que neste trabalho consideramos os cursos de Licenciatura em Computação como os cursos de formação docente em computação. Assim sendo, foram computados todos os cursos de "formação de professores para a área de computação", apesar de nem todos terem a denominação de Licenciatura em Computação. Contudo, mesmo não tendo a denominação de Licenciatura em Computação, o curso habilitava o egresso a ser um licenciado em Computação.

Por fim, este artigo está estruturado da seguinte forma: a Seção 2 apresenta alguns conceitos teóricos relevantes ao trabalho e descreve alguns trabalhos relacionados; a Seção 3 descreve o método de pesquisa utilizado; a Seção 4 apresenta os resultados obtidos neste trabalho; a Seção 5 aponta algumas discussões compreendidas a partir dos resultados gerados; e, por fim, a Seção 6 apresenta as considerações desta pesquisa.

\footnotetext{
${ }^{1}$ Para o escopo desse trabalho calculamos a evasão escolar a partir da permanência do aluno no curso, não considerando o número de vagas do curso. Isto porque queremos medir o número de alunos que evadiram dos cursos, independentemente se todas as vagas disponibilizadas no curso foram preenchidas ou não.
} 


\section{Background}

Nesta seção são apresentados o aporte teórico do trabalho, abrangendo os cursos de Licenciatura em Computação e o panorama geral sobre evasão nos cursos de graduação no Brasil. Posteriormente, também detalha os trabalhos relacionados existentes.

\subsection{Cursos de Licenciatura em Computação}

Contemporaneamente, os cursos de Licenciatura em Computação no Brasil se enquadram dentro dos cursos de Computação. Além disso, na resolução apresentada pelo MEC - Ministério da Educação e Cultura (Brasil, 2016), em seu artigo primeiro, são instituídas as diretrizes curriculares para os cursos de graduação na área da computação. Estas diretrizes devem ser observadas pelas Instituições de Educação Superior (IES) do país e visam abranger os cinco tipos de cursos de computação, que são: bacharelado em Ciência da Computação, em Sistemas de Informação, em Engenharia de Computação, em Engenharia de Software e Licenciatura em Computação.

O primeiro curso de Licenciatura em Computação foi criado no ano de 1997, na Universidade de Brasília (UnB). No entanto este era um curso específico de licenciatura, com foco na educação básica e com perspectiva de romper com modelos de formação " $3+1$ " calcados na racionalidade técnica, pelos quais se acreditava ser possível formar um professor para a educação básica por meio de complementação pedagógica (geralmente de um ano) ao final do bacharelado (Zorzo et al., 2017).

Contudo, apenas a partir do ano de 2011 os discentes dos cursos de Licenciatura em Computação passaram a fazer uma prova específica do Exame Nacional de Desempenho dos Estudantes (ENADE). Essa mudança foi de extrema importância, uma vez que inicialmente esses estudantes tinham de realizar a mesma prova aplicada aos estudantes dos cursos de bacharelado em ciência da computação. A partir de então, conteúdos pedagógicos passaram a fazer parte dessa avaliação (Zorzo et al., 2017).

De acordo com a resolução apresentada pelo MEC (Brasil, 2016), em seu artigo sexto, os currículos dos cursos de licenciatura da área da computação deverão incluir conteúdos básicos e tecnológicos referentes à área da computação. Além disso, deverão ser incluídos conteúdos de formação pedagógica, considerando as Diretrizes Curriculares Nacionais para a formação de professores para a Educação Básica.

Os cursos de licenciatura em computação têm como objetivo a formação de professores para o exercício da docência em computação na educação básica regular, profissional, tecnológica e corporativa e em outras etapas e modalidades de educação; e para atuar no projeto, no desenvolvimento, na avaliação e na gestão de sistemas educacionais e de tecnologias contemporâneas, relacionadas à computação articulada à educação (Brasil, 2016) (Brasil, 2015). Assim sendo, a introdução do pensamento computacional e algorítmico na educação básica fornece os recursos cognitivos necessários para a resolução de problemas, transversal a todas as áreas do conhecimento.

Considerando, portanto, a importância do pensamento computacional no Ensino Básico, a Sociedade Brasileira de Computação (SBC) apresenta referenciais de Formação para os cursos de graduação em computação, com base nas Diretrizes Curriculares existentes (Brasil, 2015). Estas diretrizes são um conjunto de documentos que podem auxiliar coordenadores de curso de graduação na elaboração de projetos pedagógicos (Zorzo et al., 2017).

No documento apresentado em Zorzo et al. (2017), é proposta uma organização curricular em que a interdisciplinaridade está presente desde o seu planejamento, permeando as competências, conteúdos, processos e pessoas nos cursos de Licenciatura em Computação. É proposto que os conteúdos dos cursos sejam organizados em seis eixos, de forma que estes conteúdos sejam 
agrupados de acordo com a natureza das necessidades e questões reais dos licenciados em computação, suas transformações e possibilidades técnicas e tecnológicas. Os eixos propostos são:

1. Fundamentos da Educação e suas Tecnologias;

2. Fundamentos da Computação;

3. Comunicação e Expressão;

4. Formação Docente e Tecnologias Contemporâneas;

5. Tecnologias na Educação;

6. Formação Humanística, Social e Empreendedora.

Dessa forma, percebe-se a importância do pensamento computacional no Ensino Básico e principalmente a necessidade de cursos que formem profissionais capacitados para desenvolvê-lo junto aos alunos. Contudo, apesar da crescente importância de tais cursos, percebe-se que os cursos de licenciatura em computação apresentaram, nos últimos anos, um aumento na taxa de evasão.

\subsection{Evasão nos Cursos de Ensino Superior}

A evasão no ensino superior é um problema que afeta tanto IES públicas quanto privadas. Cada indivíduo que ingressa na IES e não conclui a graduação gera uma perda de recursos financeiros, além de apontar problemas sociais e problemas vigentes nas instituições (Lobo, 2006).

A evasão escolar é um fenômeno complexo, com causas multifatoriais. Desde questões pessoais e individuais, acadêmicas e pedagógicas até a gestão universitária (Costa, Bispo e Pereira, 2018). Além disso, abrange questões sociais, financeiras e outras questões institucionais. Consequentemente, a evasão escolar tem se mostrado um fenômeno multidimensional e aspectos regionais devem ser considerados (Fritsch, Rocha e Vitelli, 2015; Lobo, 2006).

Devido a este fenômeno, foi criada uma Comissão Especial de Estudos sobre evasão nas Universidades Públicas Brasileiras pelo Ministério da Educação e Cultura em 1995. A comissão define evasão como a saída definitiva do aluno do seu curso de origem sem conclúi-lo. Na mesma linha, Lassibille e Gómez (2008) definem evasão como o abandono de um determinado programa, independentemente da motivação da partida. Considerando essa definição, há três modalidades possíveis de evasão (ANDIFES/ABRUEM/SESu/MEC, 1996):

- evasão do curso: quando o aluno sai do curso e não se rematrícula em seu curso por qualquer motivo, por exemplo, se transferindo para outro curso;

- evasão da instituição: quando o aluno deixa a instituição de ensino;

- evasão do sistema de ensino superior: quando o aluno sai, temporariamente ou definitivamente, do ensino superior.

No escopo deste trabalho estamos trabalhando apenas com a evasão de curso, uma vez que não avaliamos o destino do aluno quando este abandona o curso. Outro ponto importante a se considerar sobre a evasão é sua fórmula de cálculo. A comissão do MEC utiliza o método "tempomédio" para calcular a taxa percentual de evasão nos cursos, expresso pela equação (1) (Lassibille e Gómez, 2008):

$$
\% \text { de evasão }=[N V P v-N A V] / N V P v] 100
$$

Sendo que, NVPv é o número de vagas por vestibular nos anos correspondentes ao tempo médio de conclusão do curso e NAV o número de alunos vinculados correspondentes ao mesmo 
tempo médio. Este método utilizado pelo MEC traz resultados quantitativos em relação à evasão, em uma porcentagem por curso.

Outro método que pode ser usado para calcular a taxa de evasão em um curso é o cálculo do Instituto Lobo para Desenvolvimento da Educação, da Ciência e da Tecnologia, que toma como base a evasão anual do conjunto dos cursos, dependendo dos dados oficiais disponibilizados (Lobo, 2006), conforme é apresentado na equação 2:

$$
P=[M(n)-\lg (n)] /[M(n-1)-e g(n-1)
$$

$\mathrm{P}=$ permanência; $\mathrm{M}(\mathrm{n})$ = matrículas em algum ano; $\mathrm{M}(\mathrm{n}-1)$ = matrículas do ano anterior a $\mathrm{n}$; e $g(n-1)=$ egressos do ano anterior; $\lg (n)=$ novos ingressos no ano. Assim a taxa de evasão é a diferença da taxa de permanência em relação a 100\%.

No escopo desse trabalho calculamos a evasão escolar a partir da permanência do aluno no curso, não considerando o número de vagas. Isto porque queremos medir o número de alunos que evadiram dos cursos, independentemente se todas as vagas disponibilizadas foram preenchidas ou não.

\subsection{Censo da Educação Superior}

A principal fonte de dados sobre ensino superior no Brasil está disponível no site do Instituto Nacional de Estudos e Pesquisas Educacionais Anísio Teixeira- INEP ${ }^{2}$, batizado de Censo do Ensino Superior. Este censo reúne informações sobre instituições de ensino superior, cursos a distância e presenciais, bem como informações sobre os alunos e vagas oferecidas na graduação.

Os dados são coletados a partir de questionários de preenchimento pelas IES e importados pelo Sistema MEC. Durante o período de preenchimento do questionário, pesquisadores institucionais podem fazer as alterações ou acréscimos necessários aos dados de suas respectivas instituições a qualquer momento. Após esse período, o INEP verifica a consistência das informações coletadas e, por fim, o sistema é reaberto para verificação e validação de dados pelas IES.

\subsection{Trabalhos Relacionados}

$\mathrm{Na}$ literatura existem diversos estudos que focam na análise de cursos de licenciatura em computação, em especial na análise do fenômeno da evasão. Como exemplo temos Calixto (2015), que realiza um estudo sobre os principais fatores que contribuem para a evasão em cursos a distância, tendo como objeto o curso virtual de licenciatura em computação da Universidade Federal da Paraíba (UFPB). Neste estudo também é discutido o processo de expansão dos cursos a distância no Brasil e a percepção dos tutores sobre a evasão. Outro estudo que segue na mesma linha é apresentado por Prietche e Pazeto (2010), que visa a entender os motivos que levam a evasão a ocorrer em cursos de licenciatura em computação. No estudo, questionários são aplicados a professores e alunos, levantando dados sobre as percepções de grupos integrantes do curso na Universidade Federal Rural de Pernambuco e identificando alguns problemas que podem ser corrigidos, como forma de diminuir a alta taxa de evasão. $\mathrm{O}$ estudo ainda apresenta algumas possíveis soluções que podem auxiliar a minimizar a taxa de evasão.

Outro estudo que visa a analisar os motivos da evasão nos cursos de computação foi desenvolvido por Vasconcelos e Andrade (2018). Eles apresentam os reais anseios dos alunos, bem como suas frustrações no que tange às expectativas almejadas ao ingressarem no curso. Para tanto, faz-se um confronto entre informações de instituições do ensino público com o privado, com o intuito de analisar e verificar as divergências existentes com os resultados demonstrados

\footnotetext{
${ }^{2} \mathrm{http} / / /$ portal.inep.gov.br/microdados
} 
no curso de Licenciatura Plena em Informática do Campus Universitário de Rondonópolis (CUR), Universidade Federal de Mato Grosso (UFMT) (Vasconcelos e Andrade, 2018).

Contudo, a investigação sobre dados de cursos superiores, em especial sobre evasão. não é tema abordado apenas em cursos de licenciatura em computação. No trabalho de Saraiva, Dantas e Rodrigues (2019) é realizado um estudo para investigar a evasão do ponto de vista social e humano em cursos de sistemas de informação. Analisando os dados coletados por meio de uma pesquisa com 54 alunos durante todo o curso, eles indicaram que os dois motivos eram a estrutura geral dos cursos (ou seja, degradação ou falta de infraestrutura adequada ou o período do curso, que torna problemático combiná-lo com programas de estágio) e a falta de interesse (ou seja, alunos que estavam em sua segunda graduação ou aqueles que simplesmente decidiram mudar para outros cursos). Isso está de acordo com as conclusões de Slhessarenko, Gonçalo, Beira e Cembranel (2014), que também incluem outras razões, como a didática dos professores, expectativas não alcançadas sobre o curso, ensino inadequado na sala de aula e falta de orientação adequada do coordenador do curso.

Brito, Medeiros, Bezerra e Barbosa (2020) apresentam uma abordagem de Learning Analytics para identificar alunos propensos à evasão na modalidade EaD. Foi desenvolvido um plugin para o ambiente AVA Moodle que coleta dados de indicadores referentes aos acessos, às interações e às notas dos alunos, gerando relatórios, de forma a auxiliar a identificar alunos que possam estar em vias de abandonar o curso.

Hoffmann Nunes e Muller (2019) propõem uma sistematização para a análise da evasão, utilizando como fonte de dados o censo dos anos de 2009 a 2014. Apesar de o trabalho se propor a analisar a evasão a partir dos dados do censo, são apresentadas análises referentes à evasão apenas da Universidade de Federal de Santa Maria, e para tanto, os dados foram obtidos diretamente da IES.

Barreto, de Matos, da Hora e de Vasconcelos (2019) visam à identificação do comportamento de alunos evadidos de cursos superiores em uma instituição de ensino federal, e para esta finalidade são utilizadas técnicas de mineração de dados.

Por fim, Saccaro, França e Jacinto (2019) analisam variáveis que influenciam na evasão por meio dos dados do Censo da Educação Superior dos anos de 2009 a 2014, utilizando o método estatístico de análise de sobrevivência. Neste trabalho foram selecionados 237.697 estudantes que ingressaram no ano de 2009 em instituições privadas e públicas em cursos de graduação presenciais de bacharelado nas áreas de ciência, matemática e computação e engenharia, produção e construção.

Percebe-se que, embora os trabalhos apresentados abordem questões importantes e relevantes, a grande maioria dos estudos ficam restritos às suas universidades. Além disso, concentraram suas análises no exame do fenômeno da evasão em si, sob diferentes perspectivas. Portanto, esse trabalho apresenta diferenças significativas em ralação aos trabalhos apresentados. Como exemplo, apenas o trabalho de Saccaro, França e Jacinto (2019) utiliza dados do Censo da Educação Superior; no entanto, utilizam apenas uma amostra dos dados.

Por outro lado, em nosso trabalho é apresentada uma abordagem para conduzir tais análises em nível nacional, que incluem processos de Extração, Transformação e Carga (ETC), modelagem dimensional e Data Warehouse, de forma a preparar os dados para serem utilizados em uma ferramenta de Business Intelligence. Com isso é possível realizar análises sob diferentes perspectivas e granularidades, utilizando-se de diferentes critérios e composições, o que permitiu realizar análises em âmbito nacional dos cursos de licenciatura em computação a partir de dados do Censo da Educação Superior de diferentes anos.

Além disso é possível estender a abordagem para realizar análises com dados de diferentes cursos e incorporar dados de outros anos do Censo da Educação Superior. Por fim, a estruturação 
analítica dos dados facilitará a aplicação de técnicas estatísticas e de aprendizagem de máquina em trabalhos futuros.

\section{Método de Pesquisa}

Neste trabalho foi utilizado o Design Science Research (DSR) de forma a desenvolver um método para análise de dados públicos baseado em BI. O DSR foi escolhido por se concentrar em projetar e avaliar artefatos de Tecnologia da Informação (TI) que podem ser utilizados para resolver problemas práticos e de pesquisa (Gregor e Hevner, 2013).

Para elaborar e avaliar adequadamente o artefato, seguimos o método DSR de seis etapas proposto por Peffers, Tuunanen, Rothenberger e Chatterjee (2007). Primeiramente identificamos o problema de pesquisa, ou seja, uma metodologia abrangente e adequada para apoiar as análises de dados da Educação Superior no Brasil. Em seguida desenvolvemos o artefato de TI (ou seja, o método baseado em BI) para solucionar o problema identificado. Para isso, estabelecemos uma arquitetura de software (Figura 1) que utiliza diversas ferramentas computacionais e de análises de dados. Tendo desenvolvido o artefato de TI, pôde-se avançar para a avaliação. Para esta etapa foi utilizado o método de estudo de caso, o qual o contexto foram os cursos de licenciatura em computação no Brasil, e a unidade de análise foram as métricas de alunos e dos próprios cursos (Yin, 2013).

Para criar uma visão geral dos cursos de licenciatura em computação no Brasil, construímos um DW e, a partir disso, implantamos uma solução de BI, usando o Pentaho Business Analytics ${ }^{3}$.

A solução proposta tem o objetivo de permitir diferentes análises nos dados. Para atingir esse objetivo foram necessárias várias etapas para disponibilizar os dados ao usuário final. As etapas seguiram a arquitetura apresentada na Figura 1.

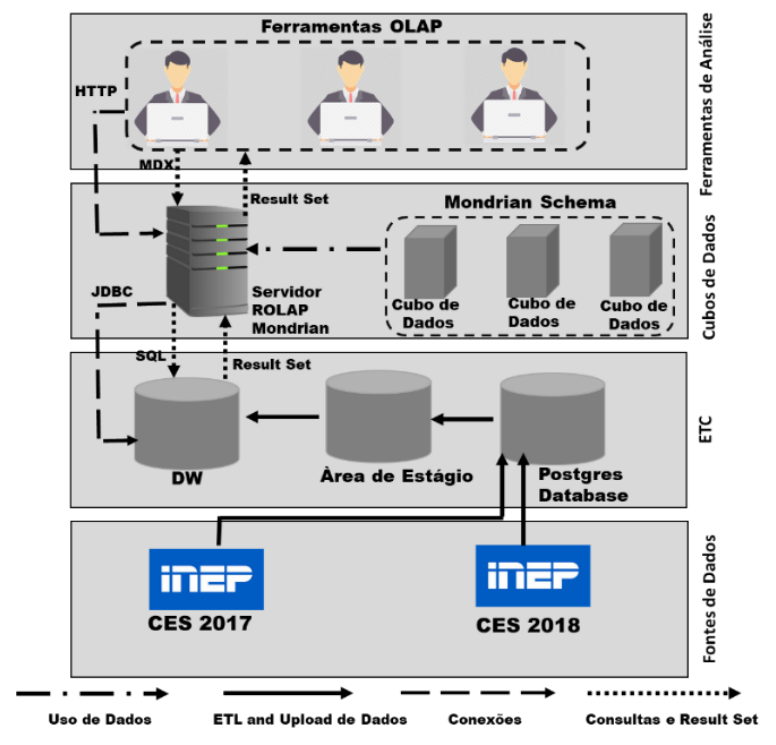

Figura 1: Arquitetura para implantar a solução de BI.

As fontes de dados primordiais foram os dados do Censo do Ensino Superior (CES) no Brasil. No site do INEP estão disponíveis para download diferentes dados sobre o ensino superior. Contudo, para este trabalho utilizamos apenas dados do CES dos anos de 2017 e 2018.

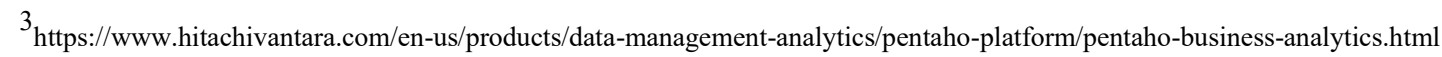


Cada base contém mais de 11 milhões de registros. Assim, após a coleta dos dados, aplicamos diversas técnicas de ETC, de forma a limpar, transformar e integrar os dados e carregá-los em um DW. O DW foi criado utilizando modelagem multidimensional. O modelo dimensional foi usado porque de acordo com Song, Rowen, Medsker e Ewen (2001), existem duas vantagens principais do uso de um modelo dimensional em ambientes de DW. Inicialmente, um modelo dimensional fornece um espaço de análise multidimensional em ambientes de banco de dados relacional. Em segundo lugar, um modelo dimensional típico e não normalizado possui uma estrutura de esquema simples que simplifica o processamento da consulta e melhora o desempenho.

O modelo dimensional físico final é composto por quatro tabelas de fatos (cor cinza) e cinco dimensões (cor branca), conforme mostrado na Figura 2 (na Figura 2 é apresentado um modelo simplificado do modelo final, no qual não são apresentados medidas, atributos e chaves dos relacionamentos). No projeto optamos por usar dimensões desnormalizadas, com muitos atributos, mas que podem ser usadas mais do que uma vez com nomes diferentes nos cubos na camada Cubos de Dados. Esse tipo de dimensão é chamado de dimensão de representação de papéis. Por exemplo: usamos a tabela dim_data para criar uma dimensão chamada Ano do Censo e outra chamada Ano da Admissão (Ano de Ingresso).

Uma vez que o DW foi criado e os dados carregados, é então possível criar os cubos de dados, que representam os dados em que efetivamente o usuário final interage.

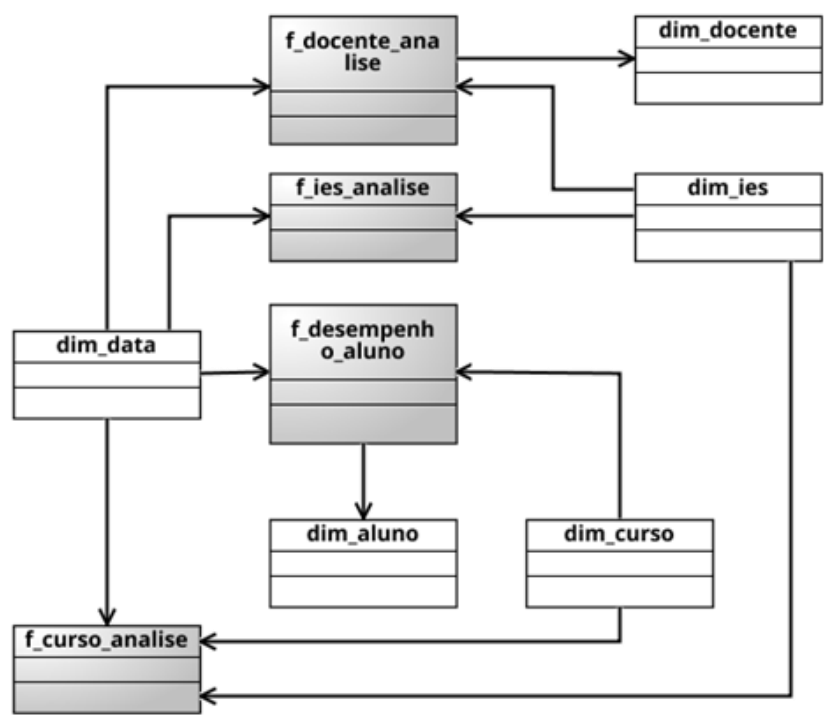

Figura 2: Modelo de dados dimensional simplificado.

Feito o DW físico, foi possível criar os cubos. Nossa solução usou o servidor Mondrian ROLAP, que é um servidor Online Analytical Processing (OLAP) de código aberto, escrito em Java. O Mondrian recebe e analisa queries na linguagem MultiDimensional Expressions (MDX) e transforma-as para Structured Query Language (SQL), de maneira a recuperar respostas para consultas dimensionais.

Depois disso, os cubos, medidas, medidas calculadas, dimensões, hierarquias, membros e níveis foram definidos criando o Esquema de Mondrian. O esquema Mondrian é composto por quatro cubos com a seguinte granularidade, número de dimensões e número de medidas:

- AlunoCurso - aluno por curso por ano, 32 dimensões e 28 medidas;

- CursoAnalise - curso por ano, 21 dimensões e 40 medidas;

- IESAnalise - universidade por ano, 5 dimensões e 57 medidas;

- DocenteInstituicao - professor por ano, 20 dimensões e 49 medidas. 
Com toda a estrutura de dados preparada, configurou-se as ferramentas da camada Ferramentas de Análise, que permite aos usuários realizarem consultas aos dados. Nesta camada foram utilizadas as ferramentas Pentaho Commnity para realizar as consultas OLAP. As ferramentas OLAP permitem análise e gerenciamento, proporcionando desempenho e acesso rápido a uma grande variedade de visualizações de dados organizadas por meio de um banco de dados multidimensional. Por exemplo: a Figura 3 exibe uma análise realizada na ferramenta OLAP BI implementada.

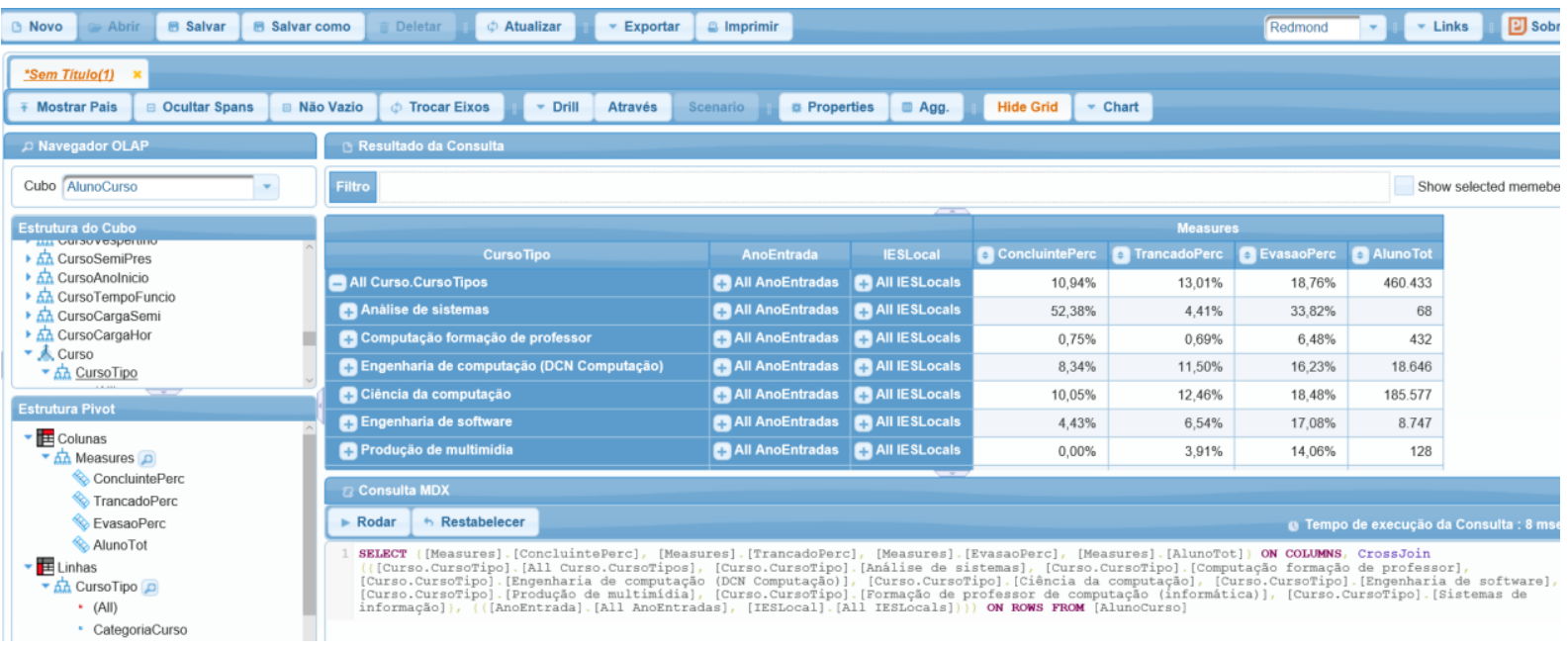

Figura 3: Consultas na ferramenta OLAP nos dados de Cursos de Computação.

Após a implantação da ferramenta foi possível realizar diversas análises, considerando todas as medidas e dimensões existentes no modelo criado, conforme apresentado na seção de análise sobre os dados em Licenciatura em Computação no Brasil.

\section{Análise sobre os dados em Licenciatura em Computação no Brasil}

Para atingir o objetivo proposto neste trabalho, nesta seção são apresentadas as análises mais relevantes para responder às questões de pesquisa propostas. Vale salientar que, para melhor compreensão dos resultados, muitas das análises foram reorganizadas após os resultados gerados pela ferramenta e outras passaram por processos estatísticos simples.

\subsection{Comparação entre Licenciatura em Computação e outros cursos de Computação}

A Tabela 1 apresenta os dados consolidados dos cursos de computação referente aos censos dos anos de 2017 e 2018, exibindo o número de cursos, estudantes, matrículas, ingressantes, alunos com matrícula trancada, concluintes e percentual de evasão.

Considerando a Tabela 1, percebe-se que restam poucos cursos com nomenclatura já não mais utilizadas, tais como cursos de Análise de Sistemas e Produção de Multimídias. Também se percebe que no censo de 2017 não existem dados sobre os cursos de Engenharia da Computação e Engenharia de Software. Contudo, no ano de 2018 existiam 104 (cento e quatro) cursos dessas duas categorias. Por meio da Tabela 1, vê-se que os cursos de Sistemas de Informação e Ciência da Computação são os cursos mais comuns de computação no Brasil, concentrando $82 \%$ dos cursos de computação e $80 \%$ dos alunos. 
Tabela 1: Número de cursos, estudantes, matrículas, evadidos, ingressantes e concluintes na área de computação nos anos de 2017 e 2018.

\begin{tabular}{|c|c|c|c|c|c|c|c|c|c|c|c|c|c|c|}
\hline \multirow[b]{2}{*}{ Curso } & \multicolumn{7}{|c|}{2017} & \multicolumn{7}{|c|}{2018} \\
\hline & $\begin{array}{c}\text { Qtd } \\
\text { Curso }\end{array}$ & Alunos & MT & IG & TR & Conc & $\begin{array}{l}\text { EV } \\
(\%)\end{array}$ & $\begin{array}{c}\text { Qtd } \\
\text { Curso }\end{array}$ & Alunos & MT & IG & TR & Conc & $\begin{array}{l}\text { EV } \\
(\%)\end{array}$ \\
\hline AS & 2 & 48 & 30 & 8 & 2 & 19 & $33,3 \%$ & 2 & 20 & 12 & 7 & 1 & 3 & $35,0 \%$ \\
\hline $\mathrm{CC}$ & 376 & 91690 & 63668 & 22975 & 11667 & 6259 & $17,8 \%$ & 396 & 93887 & 64486 & 23495 & 11459 & 6617 & $19,1 \%$ \\
\hline EC & - & - & - & - & - & - & - & 64 & 18646 & 13475 & 4077 & 2144 & 1124 & $16,2 \%$ \\
\hline ES & - & - & - & - & - & - & - & 40 & 8747 & 6681 & 2973 & 572 & 296 & $17,1 \%$ \\
\hline LC & 96 & 16081 & 12084 & 6093 & 1421 & 1070 & $16,0 \%$ & 0 & 0 & 0 & 0 & 0 & 0 & $20,8 \%$ \\
\hline PM & 1 & 48 & 43 & 28 & 1 & 0 & $17,5 \%$ & 1 & 80 & 62 & 35 & 4 & 0 & $17,5 \%$ \\
\hline SI & 575 & 108980 & 71609 & 26066 & 16178 & 9156 & $19,4 \%$ & 589 & 103628 & 69027 & 23905 & 14674 & 8725 & $19,2 \%$ \\
\hline Tot & 1053 & 218775 & 148724 & 55741 & 29555 & 16614 & $18,5 \%$ & 1195 & 241658 & 165450 & 58373 & 30332 & 17747 & $19,0 \%$ \\
\hline
\end{tabular}

Alunos - Total de Alunos, MT - Total de Matriculados, IG - Total de Ingressos, TR - Total de Trancados, Conc -Total de Concluintes, EV - Evasão.

AS - Análise de Sistemas, CC - Ciência da Computação, EC - Engenharia da Computação, ES - Engenharia de Software, LC - Licenciatura em Computação, PM - Produção de Multimídias, SI - Sistemas de Informação.

Por fim, de acordo com o censo de 2018 existe um total de 100 cursos em Licenciatura em Computação, ou seja, $8 \%$ dos cursos de computação são dedicados à formação de professores, contendo 1.650 alunos, ou $6 \%$ do total de alunos em computação. Outra constatação, que pode ser observada na Tabela 1, é que o número de alunos e alunos matriculados no censo de 2018 reduziu nos cursos de Licenciatura em Computação em comparação com os dados apresentados no censo de 2017.

Um dado preocupante apresentado na Tabela 1 se refere à evasão também nos cursos de Licenciatura em Computação. Considerando apenas os cursos com credenciamento possível, os cursos de licenciatura apresentaram um aumento significativo na taxa de evasão entre o censo de 2017 e 2018. Além disso, no censo de 2018 é o curso da área de computação que apresenta a maior taxa de evasão, com $20.81 \%$.

Ainda com o intuito de comparar os cursos de Licenciatura em Computação com outros cursos da área de computação, na Tabela 2 é apresentada uma visão do número de cursos presencial e a distância. Os cursos de licenciatura apresentam uma taxa muito maior na modalidade "a distância" em relação aos outros cursos da área de computação. Enquanto a taxa média de cursos a distância é de 4\% para os cursos da área de computação, em Licenciatura em Computação tem-se $27 \%$ dos cursos na mesma modalidade, de acordo com os dados do censo 2018. 
Tabela 2: Número de cursos, número de cursos presenciais e a distância na área de computação nos anos de 2017 e 2018.

\begin{tabular}{|c|c|c|c|c|c|c|}
\hline \multirow[b]{2}{*}{ Curso } & \multicolumn{3}{|c|}{2017} & \multicolumn{3}{|c|}{2018} \\
\hline & N. de Cursos & Presencial & Distância & N. de Cursos & Presencial & Distância \\
\hline Análise Sistemas & 2 & 2 & 0 & 2 & 2 & 0 \\
\hline Ciência da Computação & 376 & 375 & 1 & 396 & 393 & 3 \\
\hline Engenharia da Computação & - & - & - & 64 & 62 & 2 \\
\hline Engenharia de Software & - & - & - & 40 & 37 & 3 \\
\hline Licenciatura em Computação & 96 & 71 & 25 & 100 & 73 & 27 \\
\hline Produção de Multimídia & 1 & 1 & - & 1 & - & - \\
\hline Sistemas de Informação & 575 & 560 & 15 & 589 & 568 & 21 \\
\hline Tecnologia da Informação & 3 & 3 & - & 3 & 3 & - \\
\hline Todos & 1053 & 1012 & 41 & 1195 & 1138 & 56 \\
\hline
\end{tabular}

A Tabela 3 apresenta dados específicos sobre os cursos e alunos de Licenciatura em Computação. Vale ressaltar que o número de alunos em cursos presenciais, comparando os dados de 2017 e 2018, diminuiu, enquanto o número de alunos em cursos a distância aumentou. Esses números são consoantes com os dados do INEP, mostrando o crescimento da educação a distância no ensino superior no Brasil (Brasil, 2019).

Tabela 3: Número de cursos, estudantes, matriculados e evasão nos cursos de licenciatura presencial e a distância nos censos de 2017 e 2018

\begin{tabular}{|c|c|c|c|c|c|c|c|c|}
\hline & \multicolumn{4}{|c|}{2017} & \multicolumn{4}{|c|}{2018} \\
\hline & $\begin{array}{c}\text { N. de } \\
\text { Cursos }\end{array}$ & $\begin{array}{c}\text { Estudantes } \\
\text { Total }\end{array}$ & Matriculados & $\begin{array}{c}\text { Evasão } \\
(\%)\end{array}$ & $\begin{array}{c}\text { N. de } \\
\text { Cursos }\end{array}$ & $\begin{array}{c}\text { Estudantes } \\
\text { Total }\end{array}$ & Matriculados & $\begin{array}{c}\text { Evasão } \\
(\%)\end{array}$ \\
\hline Distância & 25 & 7800 & 5994 & $14,55 \%$ & 27 & 8158 & 5529 & $21,39 \%$ \\
\hline Presencial & 71 & 8281 & 6090 & $17,40 \%$ & 73 & 8492 & 6178 & $20,25 \%$ \\
\hline Todos & 96 & 16081 & 12084 & $16,02 \%$ & 100 & 16650 & 11707 & $20,81 \%$ \\
\hline
\end{tabular}

Percebe-se que a taxa de evasão nos cursos em Licenciatura em Computação aumentou consideravelmente do censo 2017 para o censo de 2018. Além disso, em 2017 a evasão era maior nos cursos presenciais; contudo, no censo de 2018 essa situação se inverteu.

\subsection{Cursos e Alunos em Licenciatura em Computação no Brasil}

A Tabela 4 apresenta dados sobre o perfil dos alunos em Licenciatura em Computação. Considerando os dados de 2017, a evasão de alunos que apresentavam alguma deficiência era ligeiramente superior à média do curso. Já no censo de 2018 não houve mais diferença. Ainda com relação aos alunos com algum tipo de deficiência, estes apresentam uma idade média superior à idade média dos demais alunos que cursam cursos de Licenciatura em Computação. 
Tabela 4: Número de estudantes, matriculados, Idade Média e evasão de acordo com características dos alunos nos cursos de licenciatura nos censos de 2017 e 2018 .

\begin{tabular}{ll|cccc|cccc} 
& & \multicolumn{9}{c|}{$\mathbf{2 0 1 7}$} & \multicolumn{5}{c}{$\mathbf{2 0 1 8}$} \\
\cline { 3 - 10 } Análise & Categorias & $\begin{array}{c}\text { N. } \\
\text { Estudantes }\end{array}$ & Matric. & $\begin{array}{c}\text { Idade } \\
\text { Média }\end{array}$ & $\begin{array}{c}\text { Evasão } \\
(\mathbf{\%})\end{array}$ & $\begin{array}{c}\text { N. } \\
\text { Estudantes }\end{array}$ & $\begin{array}{c}\text { Matric. } \\
\text { Idade } \\
\text { Média }\end{array}$ & $\begin{array}{c}\text { Evasão } \\
(\%)\end{array}$ \\
\hline Deficiente & Deficiente & 143 & 108 & 32,70 & $17,48 \%$ & 160 & 116 & 32,30 & $20,00 \%$ \\
& Amarela & 226 & 178 & 30,40 & $15,04 \%$ & 265 & 212 & 30,92 & $14,34 \%$ \\
& Branca & 4.939 & 3.808 & 30,50 & $16,54 \%$ & 5.028 & 3.386 & 30,80 & $23,89 \%$ \\
Etnia & Indígena & 95 & 60 & 29,20 & $23,16 \%$ & 102 & 69 & 29,36 & $20,59 \%$ \\
& Não Decl. & 3.004 & 2.212 & 29,59 & $17,68 \%$ & 2.872 & 2.113 & 29,44 & $21,97 \%$ \\
& Pardo & 6.328 & 4.665 & 29,74 & $15,03 \%$ & 6.802 & 4.809 & 29,72 & $18,24 \%$ \\
& Negro & 1.489 & 1.161 & 29,52 & $14,84 \%$ & 1.581 & 1.118 & 29,77 & $21,06 \%$ \\
Gênero & Feminino & 5.116 & 3.901 & 30,30 & $15,03 \%$ & 5.197 & 3.633 & 30,17 & $21,19 \%$ \\
& Masculino & 10.965 & 8.183 & 29,76 & $16,48 \%$ & 11.453 & 8.074 & 29,95 & $20,64 \%$ \\
Ensino & Privada & 5.076 & 3.806 & 30,96 & $14,48 \%$ & 5.365 & 3.703 & 30,87 & $20,11 \%$ \\
Médio & Pública & 10.618 & 7.969 & 29,26 & $16,75 \%$ & 11.021 & 7.822 & 29,46 & $20,92 \%$ \\
& Não Def. & 387 & 309 & 34,89 & $16,28 \%$ & 264 & 182 & 36,11 & $30,30 \%$ \\
Total & & 16.081 & 12.084 & 29,93 & $16,02 \%$ & 16.650 & 11.707 & 30,02 & $20,81 \%$ \\
\hline
\end{tabular}

N. Estudantes - Número total de estudantes no curso, Matric. - Número de alunos efetivamente matriculados no curso.

Com relação à etnia, a maioria dos alunos são brancos ou pardos. Essas duas etnias representaram mais de $70 \%$ dos alunos matriculados, tanto no censo do ano de 2017 quanto de 2018. No censo de 2017 a evasão de alunos indígenas era superior à de alunos de outras etnias, diferença essa que não se manteve em 2018. Por outro lado, a evasão de alunos brancos se tornou a maior entre todas as etnias.

Com relação ao antecedente escolar dos alunos em Licenciatura em Computação, percebe-se que a maioria deles estudou em escola pública. No Censo de 2017 era possível perceber que a evasão de alunos advindos de escolas privadas era inferior aos demais alunos, contudo essa situação não se manteve no censo de 2018.

Percebe-se, também, que a evasão de alunos do gênero feminino não apresenta diferença significativa em relação à dos alunos do gênero masculino. Contudo, é importante salientar que o número de alunos do gênero feminino é bem inferior ao do gênero masculino, mas ao observar a Tabela 5, nota-se que apesar desse número ser inferior, os cursos de licenciatura apresentam um número de alunos do gênero feminino muito superior à média dos cursos de computação.

Por meio ainda da Tabela 5, é possível observar que a idade média dos alunos em Licenciatura em Computação é superior aos demais estudantes de outros cursos de computação. 
Tabela 5: Proporção de alunos do gênero masculino e feminino e idade média dos alunos nos cursos de computação, considerando o censo 2018.

\begin{tabular}{lcc|c}
\cline { 2 - 4 } \multicolumn{1}{c}{ Curso } & \multicolumn{2}{c}{ Estudantes (\%) } & Idade Média \\
\cline { 2 - 4 } & Feminino. & Masculino & Geral \\
\hline Licenciatura em Computação & $31,81 \%$ & $68,19 \%$ & 30,02 \\
Ciência da Computação & $11,06 \%$ & $88,94 \%$ & 24,85 \\
Engenharia da Computação & $11,29 \%$ & $88,71 \%$ & 23,30 \\
Engenharia de Software & $11,72 \%$ & $88,28 \%$ & 24,35 \\
Sistemas de Informação & $13,89 \%$ & $86,11 \%$ & 25,64 \\
Todos & $13,71 \%$ & $86,29 \%$ & 24,91 \\
\hline
\end{tabular}

A Tabela 6 apresenta a taxa de cursos a distância e presencial dos cursos de licenciatura.

Tabela 6: Taxa de cursos presenciais e a distância, tempo médio de operação e média de horas nos cursos em Licenciatura em Computação de acordo com a característica da IES para o censo de 2018.

\begin{tabular}{llccc} 
Tipo IES & Modalidade Ensino & Porc. de Cursos & Tempo Médio de Oper. & Média de Horas \\
& & & & \\
\hline \multirow{2}{*}{ Privado } & Distância & $22,2 \%$ & 13,67 & 3301 \\
& Presencial & $28,77 \%$ & 14,85 & 3212 \\
Público & Distância & $77,78 \%$ & 17,29 & 3290 \\
Especial & Presencial & $71,23 \%$ & 13,43 & 3246 \\
\hline \multicolumn{2}{l}{ Porc. de Cursos - Porcentagem de curso em cada modalidade, Tempo Médio de Oper. - Tempo médio que os } \\
\multicolumn{4}{l}{} \\
cursos na modalidade estão em funcionamento (em anos).
\end{tabular}

Percebe-se que as IES públicas apresentam a maioria dos cursos na modalidade presencial e a maioria absoluta na modalidade a distância, chegando a mais de $80 \%$ desta modalidade no censo de 2018.

A Tabela 7 apresenta dados referentes aos estudantes e cursos de acordo com o tipo de instituição, região do curso, período do curso e tipo de entrada do aluno. Primeiramente é possível observar que apesar do número de cursos a distância ser aproximadamente um quarto dos cursos presenciais, estes têm quase o mesmo número de alunos matriculados.

$\mathrm{Na}$ análise das regiões estão sendo considerados apenas os cursos presenciais. As regiões com o maior número de cursos e alunos matriculados são, respectivamente, a região Nordeste e Norte. Dentre essas regiões destacam-se os estados da Bahia, com seis cursos, Pará e Tocantins, com cinco curso cada, e Pernambuco, com quatro cursos.

Com relação ao tipo de Instituição, percebe-se que as IES públicas têm mais de $70 \%$ dos cursos credenciados em Licenciatura em Computação no Brasil. Além disso, estas IES têm mais de $80 \%$ dos alunos matriculados nos cursos. Por fim, percebe-se uma grande diferença entre a evasão na IES públicas e privadas.

Por meio da Tabela 7 observou-se que os cursos em Licenciatura em Computação no Brasil operam essencialmente no período noturno e, por fim, têm-se que em torno de $18 \%$ dos alunos matriculados entraram por meio de alguma forma de reserva de vagas e que a evasão destes alunos é menor do que a evasão de alunos que ingressaram por outros meios. Vale salientar que a maioria da entrada por meio de reserva de vagas ocorre em IES públicas. 
Tabela 7: Dados referentes aos estudantes e cursos, de acordo com o tipo de instituição, região do curso, período do curso e tipo de entrada do aluno referente ao censo de 2018.

\begin{tabular}{|c|c|c|c|c|c|c|c|c|}
\hline \multirow[b]{2}{*}{ Análise } & \multirow[b]{2}{*}{ Categoria } & \multicolumn{4}{|c|}{ Alunos } & \multicolumn{3}{|c|}{ Cursos } \\
\hline & & $\begin{array}{c}\text { Total } \\
\text { Estudantes }\end{array}$ & Matriculados & $\begin{array}{l}\text { Idade } \\
\text { Média }\end{array}$ & $\begin{array}{c}\text { Evasão } \\
(\%)\end{array}$ & $\begin{array}{l}\text { N. de } \\
\text { Cursos }\end{array}$ & $\begin{array}{l}\text { Tempo } \\
\text { Médio de } \\
\text { Oper. }\end{array}$ & $\begin{array}{l}\text { Média } \\
\text { de } \\
\text { Horas }\end{array}$ \\
\hline \multirow{2}{*}{$\begin{array}{l}\text { Método de } \\
\text { Ensino }\end{array}$} & Distância & 8158 & 5529 & 32,56 & $21,39 \%$ & 27 & 13,85 & 3.295 \\
\hline & Presencial & 8492 & 6178 & 27,57 & $20,25 \%$ & 73 & 14,39 & 3.223 \\
\hline \multirow{5}{*}{ Região } & Centro-Oeste & 700 & 481 & 26,39 & $23,29 \%$ & 12 & 16,00 & 3.313 \\
\hline & Norte & 3119 & 2342 & 28,28 & $17,22 \%$ & 16 & 12,94 & 3.113 \\
\hline & Sudeste & 628 & 431 & 27,40 & $20,38 \%$ & 10 & 15,33 & 3.280 \\
\hline & Sul & 1159 & 751 & 26,62 & $28,73 \%$ & 13 & 15,54 & 3.211 \\
\hline & Nordeste & 2886 & 2173 & 27,52 & $19,37 \%$ & 22 & 13,50 & 3.234 \\
\hline \multirow{3}{*}{$\begin{array}{l}\text { Tipo de } \\
\text { Instituição }\end{array}$} & Privada & 2.923 & 1.835 & 31,89 & $31,17 \%$ & 27 & 14,51 & 3.239 \\
\hline & Pública & 14.616 & 10.564 & 29,69 & $18,74 \%$ & 72 & 14,39 & 3.257 \\
\hline & Especial & - & - & - & - & 1 & - & 3.240 \\
\hline \multirow{4}{*}{$\begin{array}{l}\text { Período } \\
\text { do Curso }\end{array}$} & Integral & 724 & 512,00 & 25,15 & $18,92 \%$ & 11 & 15,27 & 3.131 \\
\hline & Matutino & 1346 & 1023,00 & 29,12 & $19,54 \%$ & 16 & 14,13 & 3.295 \\
\hline & Vespertino & 786 & 597,00 & 32,56 & $19,08 \%$ & 5 & 19,4 & 3.216 \\
\hline & Noturno & 7388 & 5377,00 & 27,95 & $20,41 \%$ & 57 & 14,09 & 3.243 \\
\hline \multirow{2}{*}{$\begin{array}{l}\text { Entrada } \\
\text { Por } \\
\text { Reserva } \\
\end{array}$} & Sim & 2297 & 2145 & 27,68 & $16,85 \%$ & & & \\
\hline & Não & 13653 & 9562 & 30,53 & $21,68 \%$ & & & \\
\hline
\end{tabular}

N. de Cursos - Número de Cursos, Tempo Médio de Oper. - Tempo médio que os cursos estão em funcionamento (em anos).

Por fim, a Tabela 8 apresenta os dados de número de cursos, total de alunos, alunos matriculados e taxa de evasão, de acordo com as características populacionais das cidades em que os cursos operam e se a cidade é capital de estado ou não.

Tabela 8: Número de cursos, total de alunos, alunos matriculados e taxa de evasão, de acordo com as características das cidades dos cursos para os censos de 2017 e 2018.

\begin{tabular}{|c|c|c|c|c|c|c|c|c|c|}
\hline \multirow[b]{3}{*}{ Análise } & \multirow[b]{3}{*}{ Categoria } & \multirow{2}{*}{\multicolumn{4}{|c|}{2017}} & & & & \\
\hline & & & & & & \multicolumn{4}{|c|}{2018} \\
\hline & & $\begin{array}{l}\text { N. de } \\
\text { Cursos }\end{array}$ & $\begin{array}{l}\text { Total de } \\
\text { Alunos }\end{array}$ & Mat. & EV. (\%) & $\begin{array}{l}\text { N. de } \\
\text { Cursos }\end{array}$ & $\begin{array}{l}\text { Total de } \\
\text { Alunos }\end{array}$ & Mat. & EV. (\%) \\
\hline \multirow{5}{*}{$\begin{array}{l}\text { Tam. } \\
\text { Cidade }\end{array}$} & $<50.000$ & 3 & 201 & 122 & $20,87 \%$ & 3 & 282 & 119 & $41,52 \%$ \\
\hline & $\begin{array}{l}50.000<\text { cid. }< \\
100.000\end{array}$ & 4 & 141 & 102 & $17,53 \%$ & 8 & 54 & 47 & $16,13 \%$ \\
\hline & $\begin{array}{l}100.000<\text { cid. }< \\
500.000\end{array}$ & 25 & 2766 & 2101 & $18,61 \%$ & 24 & 2.804 & 2.011 & $20,78 \%$ \\
\hline & $\begin{array}{l}500.000<\text { cid. }<1 \\
\text { milhão }\end{array}$ & 10 & 1425 & 1127 & $17,07 \%$ & 9 & 1.393 & 1.015 & $20,84 \%$ \\
\hline & Mais de 1 milhão & 29 & 3748 & 2638 & $16,23 \%$ & 29 & 3.959 & 2.986 & $18,70 \%$ \\
\hline \multirow{2}{*}{ Capital } & Sim & 19 & 2.948 & 2.062 & $14,96 \%$ & 19 & 2.673 & 1.851 & $21,17 \%$ \\
\hline & Não & 52 & 5.333 & 4.028 & $18,75 \%$ & 54 & 5.819 & 4.327 & $19,83 \%$ \\
\hline
\end{tabular}

N. de Cursos - Número de Cursos, Mat. - Número de alunos matriculados, EV (\%) - Taxa de evasão. 
Essa análise leva em consideração apenas os dados dos cursos presenciais ${ }^{4}$. Por meio da Tabela 8 , percebe-se que mais de $85 \%$ dos cursos de Licenciatura em Computação presencias estão em cidades com mais de 100 mil habitantes e mais de $95 \%$ dos alunos matriculados estão nestas cidades. Por outro lado, a evasão em cidade com menos de 50 mil habitantes é superior à média das demais. Também se observa que a maioria dos cursos e alunos se concentram em cidades que não são capitais. Por exemplo, no ano de 2018 mais de $70 \%$ dos alunos matriculados em cursos de Licenciatura em Computação presenciais estavam em cidades que não são capitais. Contudo, cursos operando nestas cidades apresentam uma evasão superior aos das capitais.

A fim de investigar a evasão nos cursos de Licenciatura em Computação no Brasil e comparar com outros cursos da área de computação (bacharelado em sistemas de informação e bacharelado em ciência da computação), foi analisada a taxa de evasão, considerando o tempo de entrada do aluno no curso. Essa análise se faz importante, pois é necessário entender como a evasão ocorre ao longo dos anos e não apenas olhando os dados consolidados finais da evasão.

A Tabela 9 apresenta um comparativo da evasão entre os cursos de Sistemas de Informação (SI), Ciência da Computação (CC) e Licenciatura em Computação. Os cursos de SI e CC são utilizados para essa comparação por dois motivos principais: primeiramente são os cursos com o maior número de alunos em cursos em computação no Brasil; segundo, estes cursos apresentam dados tanto no censo 2017 quanto no 2018, o que permite fazer uma melhor análise dos dados.

Tabela 9: Taxa de evasão nos cursos de SI, CC e Licenciatura em Computação de acordo com tempo de entrado do aluno para os censos de 2017 e 2018.

\begin{tabular}{|c|c|c|c|c|c|c|c|c|c|}
\hline \multirow{2}{*}{$\begin{array}{c}\text { Tempo } \\
\text { Entrada } \\
\text { (Anos) }\end{array}$} & \multicolumn{3}{|c|}{ Sistemas de Informação } & \multicolumn{3}{|c|}{ Ciência da Computação } & \multicolumn{3}{|c|}{ Licenciatura em Computação } \\
\hline & $\begin{array}{c}\text { EV(\%) } \\
2017 \\
\end{array}$ & $\begin{array}{c}\text { EV(\%) } \\
2018 \\
\end{array}$ & $\begin{array}{l}\text { EV(\%) } \\
\text { Média }\end{array}$ & $\begin{array}{c}\mathbf{E V}(\%) \\
2017 \\
\end{array}$ & $\begin{array}{c}\operatorname{EV}(\%) \\
2018 \\
\end{array}$ & $\begin{array}{l}\text { EV(\%) } \\
\text { Média }\end{array}$ & $\begin{array}{c}\mathrm{EV}(\%) \\
2017 \\
\end{array}$ & $\begin{array}{c}\text { EV(\%) } \\
2018 \\
\end{array}$ & $\begin{array}{l}\text { EV(\%) } \\
\text { Média }\end{array}$ \\
\hline 0 & $13,58 \%$ & $14,35 \%$ & $13,97 \%$ & $15,80 \%$ & $15,41 \%$ & $15,60 \%$ & $10,68 \%$ & $13,79 \%$ & $12,23 \%$ \\
\hline 1 & $20,94 \%$ & $20,30 \%$ & $20,62 \%$ & $19,12 \%$ & $21,95 \%$ & $20,54 \%$ & $21,58 \%$ & $23,51 \%$ & $22,54 \%$ \\
\hline 2 & $19,36 \%$ & $19,79 \%$ & $19,57 \%$ & $19,11 \%$ & $21,59 \%$ & $20,35 \%$ & $17,82 \%$ & $23,73 \%$ & $20,77 \%$ \\
\hline 3 & $19,58 \%$ & $18,43 \%$ & $19,01 \%$ & $16,16 \%$ & $17,57 \%$ & $16,87 \%$ & $20,71 \%$ & $21,16 \%$ & $20,94 \%$ \\
\hline 4 & $19,91 \%$ & & $19,39 \%$ & $18,01 \%$ & & $17,83 \%$ & $17,20 \%$ & $14,40 \%$ & $15,80 \%$ \\
\hline 5 & $24,04 \%$ & $22,38 \%$ & $23,21 \%$ & $18,28 \%$ & $18,87 \%$ & $18,58 \%$ & $11,56 \%$ & $23,35 \%$ & $17,46 \%$ \\
\hline 6 & $23,38 \%$ & $26,60 \%$ & $24,99 \%$ & $19,12 \%$ & $21,07 \%$ & $20,10 \%$ & $17,91 \%$ & $26,37 \%$ & $22,14 \%$ \\
\hline 7 & $28,79 \%$ & $27,60 \%$ & $28,19 \%$ & $22,44 \%$ & $23,26 \%$ & $22,85 \%$ & $28,65 \%$ & $30,95 \%$ & $29,80 \%$ \\
\hline
\end{tabular}

Tempo Entrada (Anos) - Número de anos que o estudante deu entrada no curso, EV (\%) - Taxa de evasão.

Como pode ser observado na Tabela 9, os cursos de Licenciatura em Computação apresentam uma evasão menor que os cursos de SI e CC para ingressantes. Contudo, é possível perceber uma tendência nos dados da Tabela 9 de quanto maior o tempo de permanência no curso, maior a evasão, e esse aumento se faz mais gradativo nos cursos de Licenciatura em Computação.

\section{Discussão}

Considerando os dados apresentados na Seção 4, algumas discussões podem ser elaboradas e até mesmo alguns suposições sobre os cursos de Licenciatura em Computação no Brasil. Analisando a Tabela 1, vê-se que no ano de 2018 havia 100 cursos de Licenciatura em Computação no Brasil. De acordo com o relatório do ensino superior de informática (SBC, 2015), até 2014, 90 cursos de

\footnotetext{
${ }^{4}$ Nesta análise foram considerados apenas cursos presenciais, pois não é possível saber a localização de um curso à distância, uma vez que este pode ter vários polos espalhados. Assim, a análise da influencia do tamanho da cidade na evasão não pode ser analisada para os cursos à distância.
} 
Licenciatura em Computação estavam registrados no Brasil. Assim sendo, de 2014 a 2018 houve um aumento de $11 \%$ total destes cursos.

Outro ponto que podemos observar é que, no geral, os cursos da área de computação tiveram um aumento no número de alunos $(10,46 \%)$, alunos matriculados $(11,25 \%)$ e ingressantes $(4,72 \%)$, conforme pode ser visto na Figura 4.

Esse aumento se dá principalmente pelos cursos de Engenharia da Computação e Engenharia de Software. Além destes cursos, os cursos de Ciência da Computação também apresentaram um incremento no total de alunos, alunos matriculados e ingressantes. Contudo, os cursos de Sistemas de Informação e Licenciatura em Computação apresentam um decremento nestes dados. Licenciatura em Computação apresenta um decremento superior a 35\% de ingressantes, comparado o censo de 2017 com o de 2018.

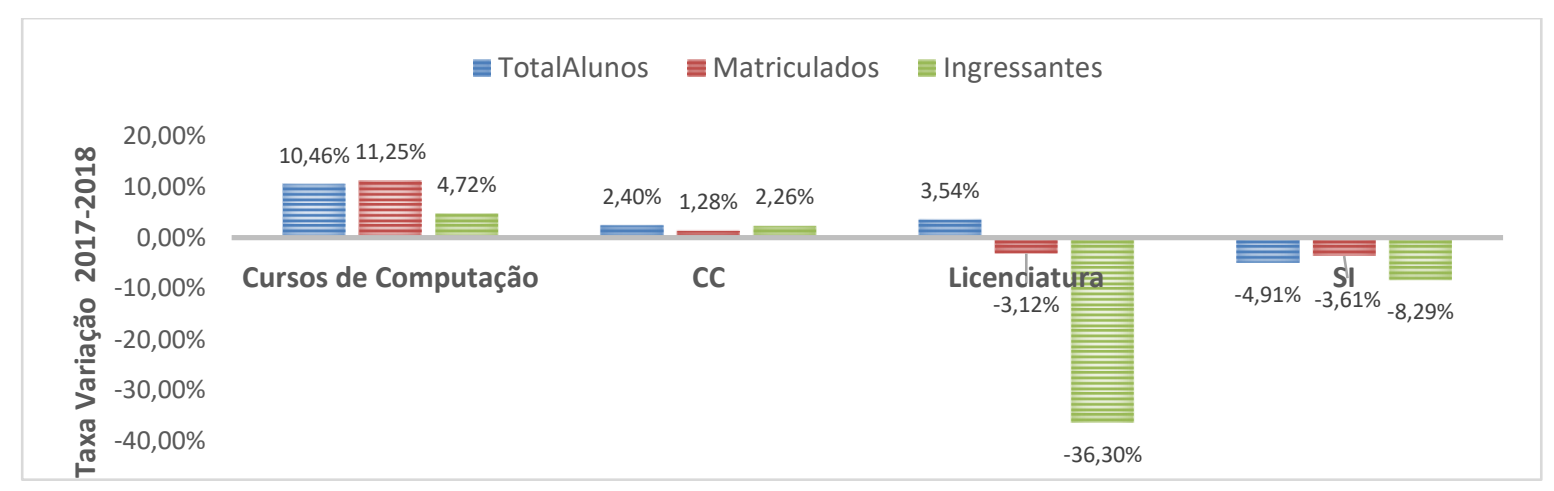

Figura 4. Taxa de variação de alunos, matriculados e ingressantes entre os censos de 2017 e 2018.

Outra análise que apresenta dados preocupantes com relação ao número de alunos em Licenciatura em Computação é mostrada na Figura 5. Essa figura mostra a relação entre o número de cursos existentes e o número de alunos em cada curso. Como pode ser observado houve um decréscimo na proporção de alunos por cursos da área de computação e os cursos de Licenciatura em Computação são os que apresentam a menor proporção.

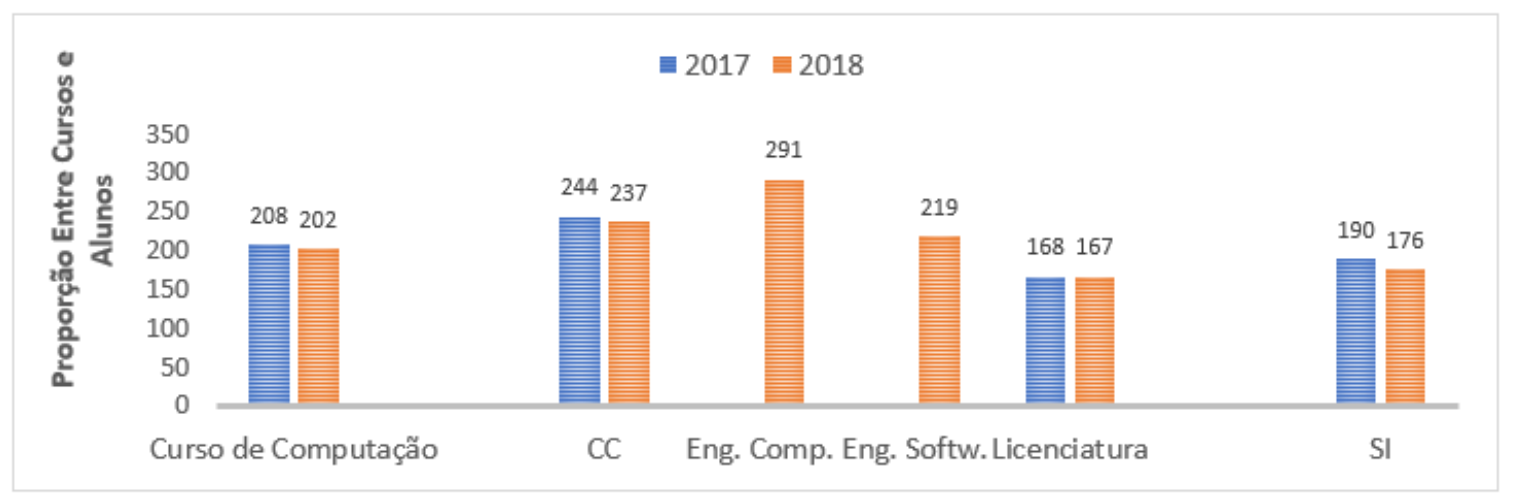

Figura 5. Proporção de alunos por curso nos cursos de computação para os censos de 2017 e 2018.

Dentro deste panorama, as IES públicas apresentam quase o dobro de alunos por curso em relação às IES privadas (203 alunos por curso - pública/ 108 aluno por curso - privadas), dados estes apresentados pelo relatório da época nos cursos de Licenciatura em Computação. Ainda com relação à proporção de alunos-curso, como era de se esperar os cursos a distância têm uma relação muito superior aos cursos presenciais neste quesito. Os cursos presenciais de Licenciatura em Computação têm, em média, 116 alunos por curso, enquanto os a distância têm a média de 302 alunos.

Outra análise que pode ser observada é em relação ao aumento de cursos entre os censos de 2017 e 2018, como apresentado na Figura 6. Como observado na Figura 6, os cursos de 
licenciatura apresentaram a menor taxa de crescimento entre os cursos da área de computação na modalidade a distância. Além disso, por meio da Figura 6 percebe-se que o aumento em cursos na modalidade a distância foi maior que os na modalidade presencial em todos os cursos analisados.

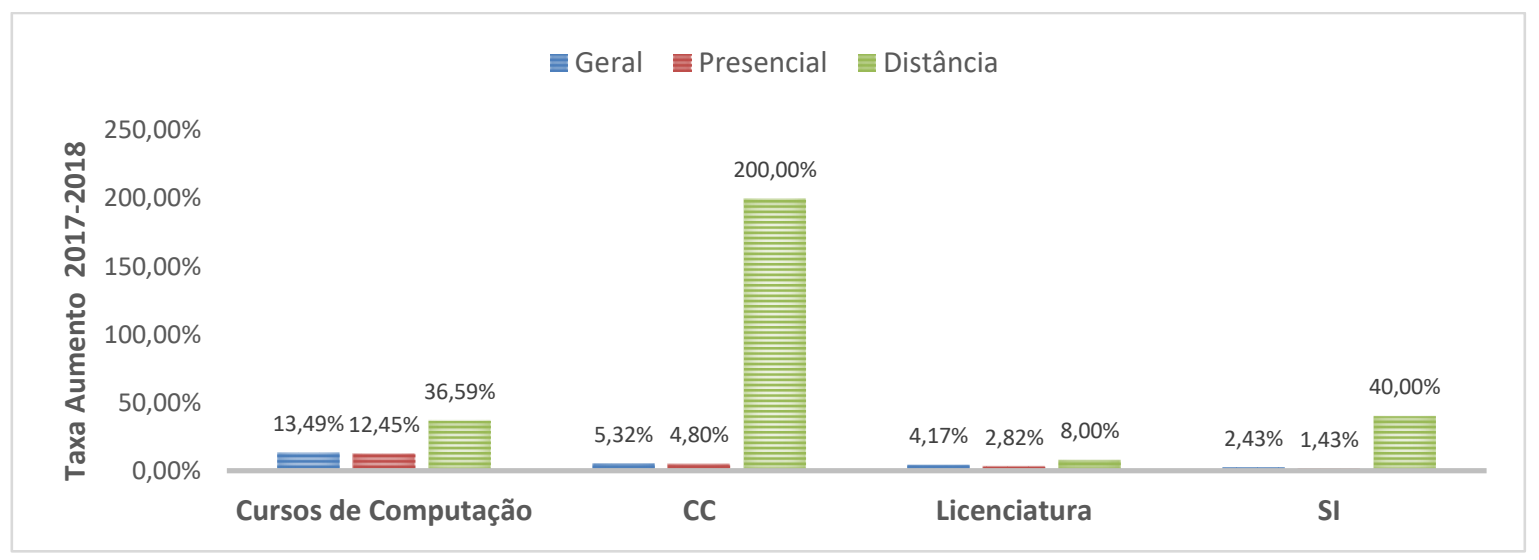

Figura 6: Taxa de aumento nos cursos entre os censos de 2017 e 2018.

Com relação ao número de alunos e cursos por região, de acordo com INEP (Brasil, 2019) as regiões que apresentavam o maior número em 2014 eram, respectivamente, a região Nordeste e a Norte, panorama este que se manteve. Por meio dos dados apresentados na Tabela 7, percebe-se, na Figura 7, que existe uma relação entre o número de cursos e alunos por região. Contudo, apesar da região Nordeste apresentar seis cursos a mais que a região Norte, esta é a que apresenta o maior número de alunos matriculados.

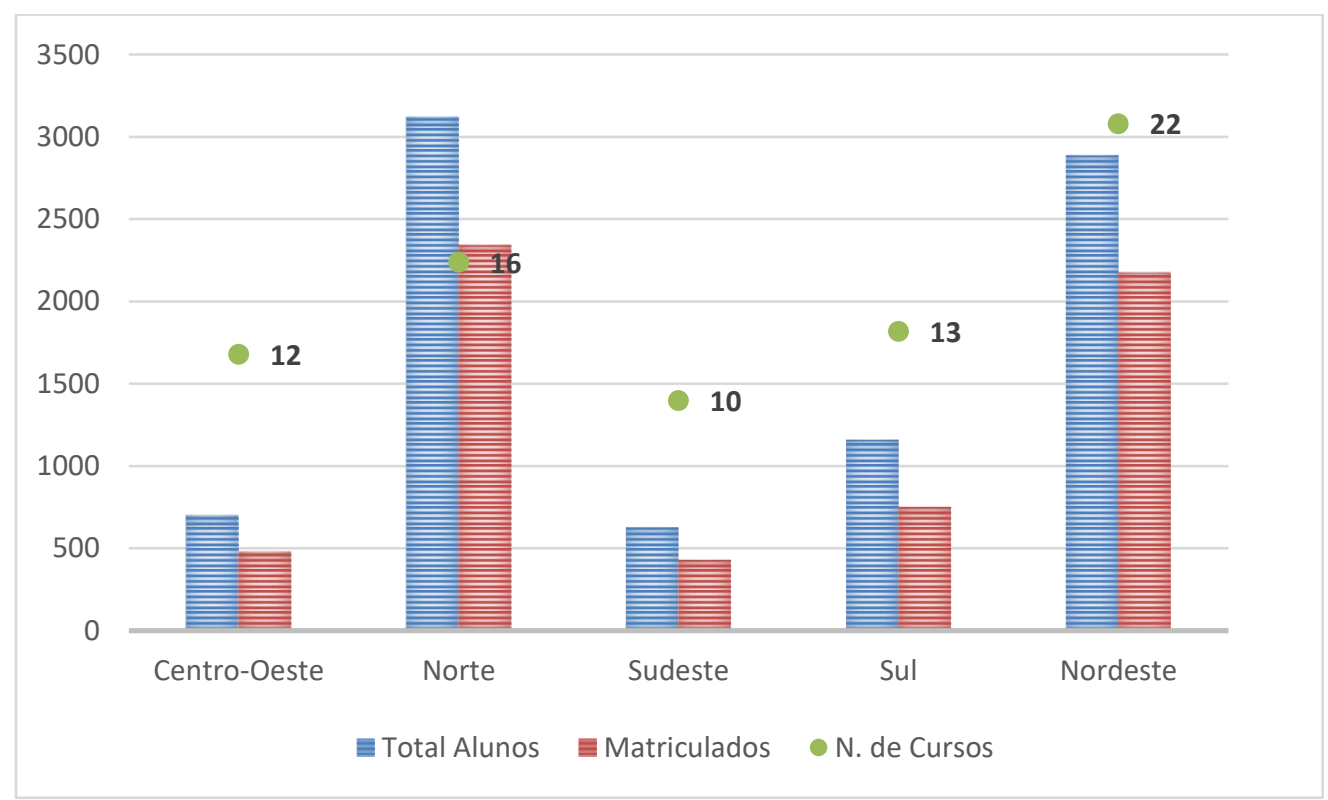

Figura 7: Número de total de alunos, matriculados e cursos por região para o censo de 2018.

Com relação à evasão, a Figura 8 apresenta a taxa nos cursos de CC, SI e Licenciatura em Computação de acordo com o tempo de entrada do aluno. Como mostrado, a evasão para os cursos de licenciatura é menor nos primeiros anos, mas quanto mais tempo o aluno permanece no curso mais a evasão aumenta, tornando-a maior do que nos cursos de SI e CC. 


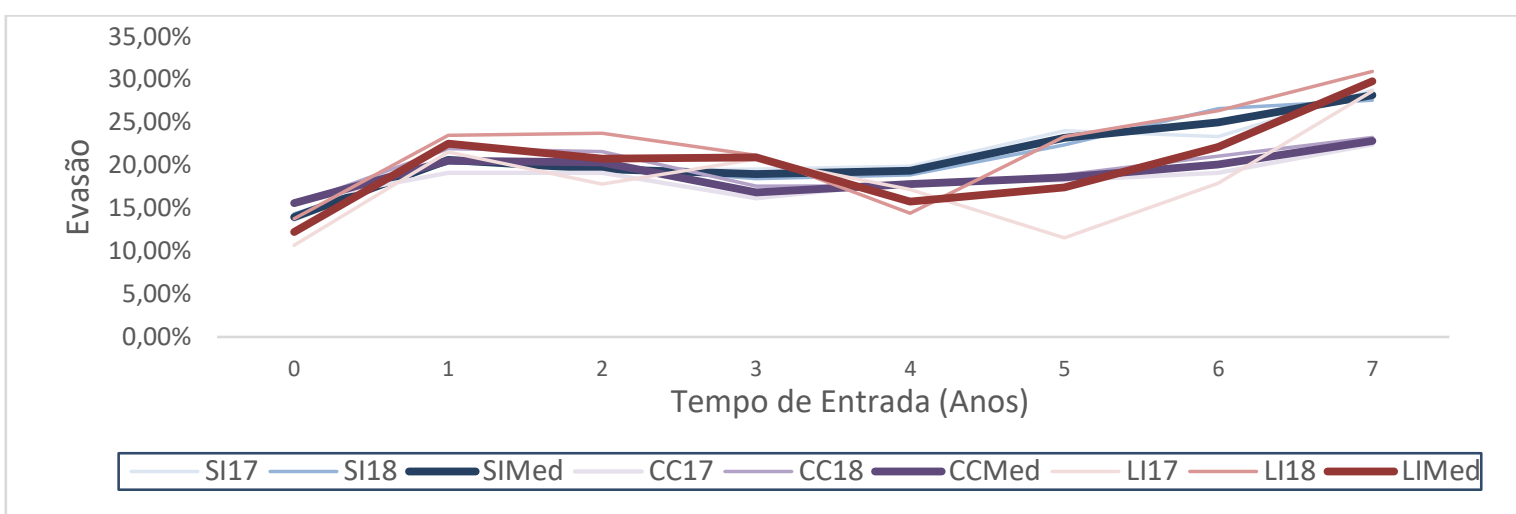

Figura 8: Taxa de evasão de acordo com o tempo de entrada para os cursos de SI, CC e Licenciatura em Computação para os censos de 2017 e 2018.

A Figura 9 apresenta como ocorre a evasão nos cursos de Licenciatura em Computação, comparando as instituições públicas e privadas, e os cursos nas modalidades presenciais e a distância. A Figura 9a apresenta como ocorre a evasão com o passar dos anos de entrada do aluno, comparando os cursos de IES públicas e privadas. Percebe-se que a evasão nas IES públicas é sempre menor que nas privadas, e essa diferença se acentua quanto mais tempo o aluno permanece no curso. Já para cursos presenciais e a distância, como mostrado na Figura 9b, até o primeiro ano a evasão em cursos a distância é menor do que em cursos presenciais. Contudo, à medida que o aluno permanece no curso estes dados se invertem e a diferença entre a evasão de cursos a distância e presencial aumenta, sendo a evasão nos cursos a distância superior.

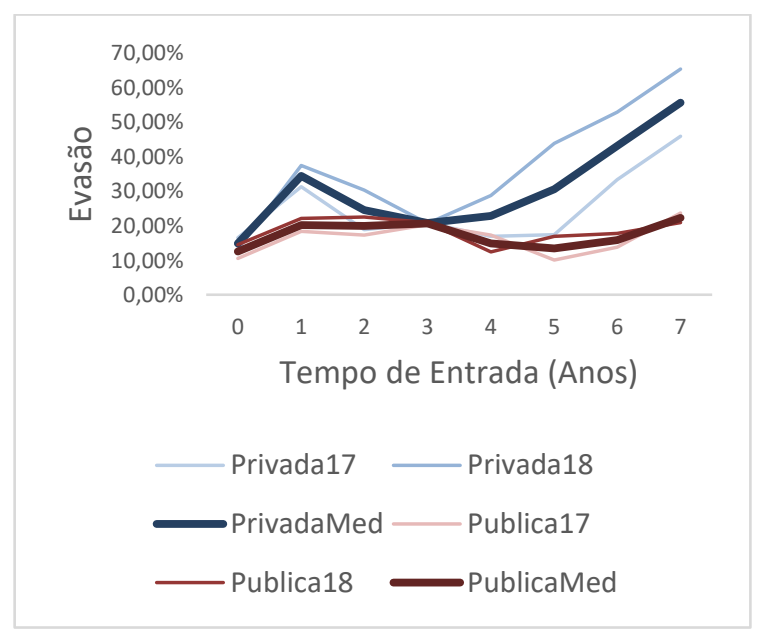

Figura 9a: Taxa de evasão entre IES públicas e privadas de acordo com o tempo de entrada para os cursos Licenciatura em Computação para os censos de 2017 e 2018.

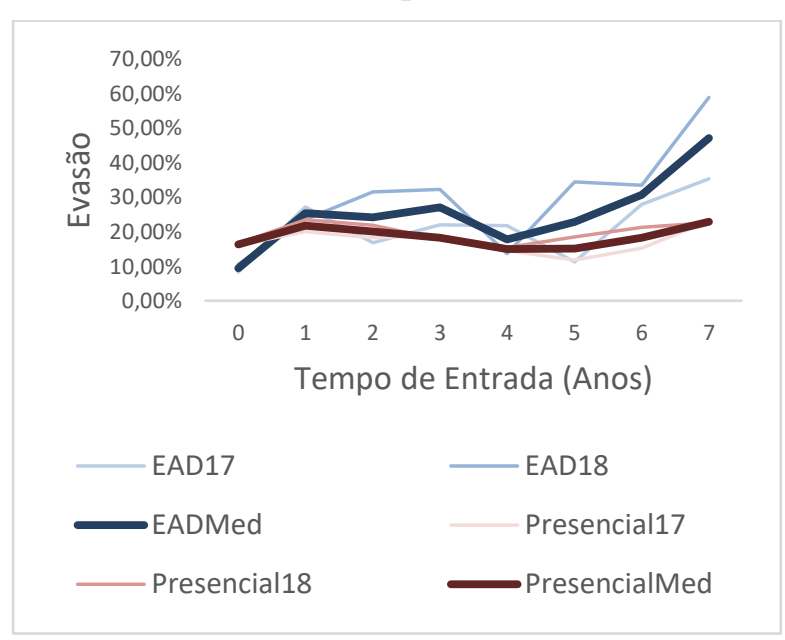

Figura 9b: Taxa de evasão entre cursos presenciais e a distância de acordo com o tempo de entrada para os cursos Licenciatura em Computação para os censos de 2017 e 2018.

Uma vez que a taxa de evasão dos cursos em Licenciatura em Computação se encontra dentro da média de outros cursos da área de computação, comparamos, também, com cursos de licenciatura de outras áreas. Na Figura 10 é apresentada uma visão geral da taxa de evasão de alguns cursos de licenciatura de diferentes áreas assim como a taxa média de evasão das áreas, de acordo com os censos de 2017 e 2018. As linhas tracejadas indicam a taxa de evasão dos cursos de Licenciatura em Computação nos anos de 2017 e 2018. 


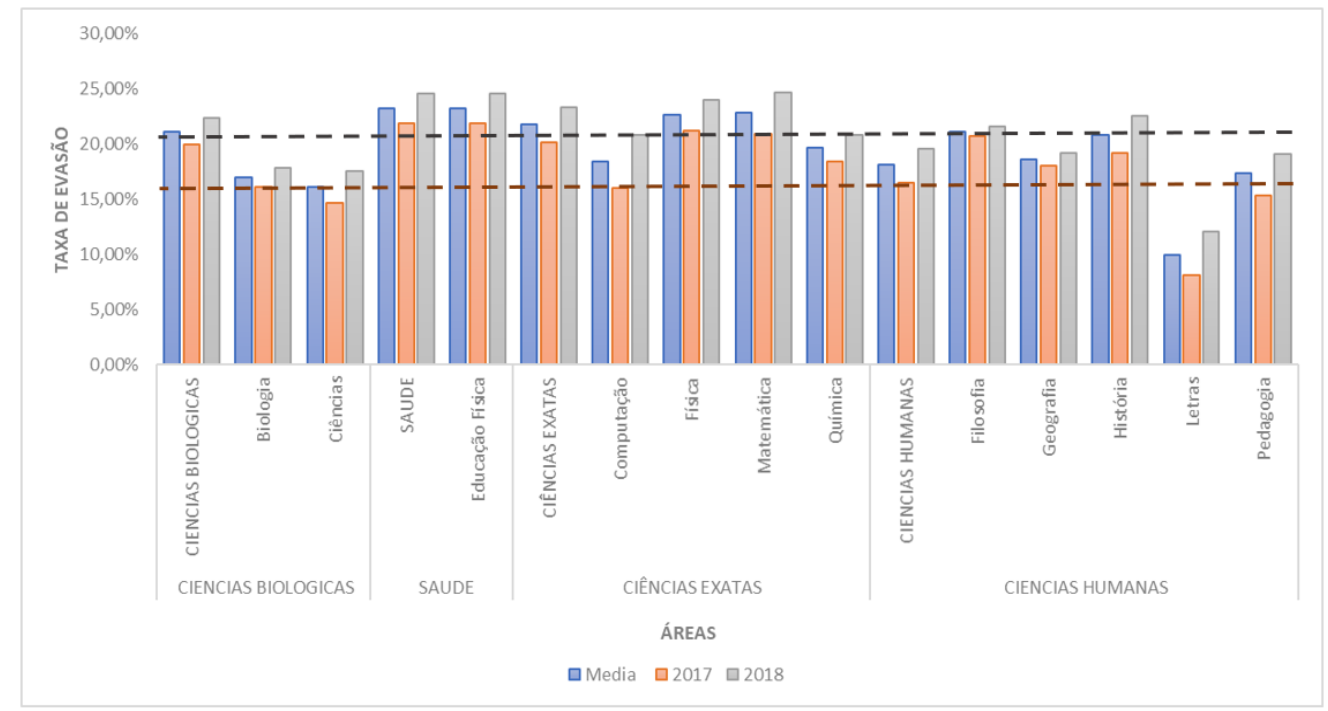

Figura 10: Taxa de evasão de cursos de Licenciatura de diferentes áreas, para os censos de 2017 e 2018.

Como pode ser visto na Figura 10, todos os cursos, independente da área, tiveram aumento da taxa de evasão do censo de 2017 para o de 2018. Os cursos de Licenciatura em Computação apresentam a menor taxa de evasão dentre os cursos da área de exatas. Além disso, a taxa de evasão dos cursos de Licenciatura em Computação é menor que a média dos cursos da área de biológicas e saúde. Comparando-se com a área de humanas, em 2017 a taxa de evasão dos cursos de Licenciatura em Computação foi equivalente e para o ano de 2018 um pouco superior.

\section{Conclusões}

Este trabalho apresentou análises de dados públicos utilizando tecnologias de Bussiness Inteligence a fim de mapear os cursos de Licenciatura em Computação no Brasil, de forma a apresentar um panorama referente ao perfil destes cursos e identificar fatores associados à taxa de evasão.

Duas questões de pesquisa foram propostas a partir do objetivo geral proposto. Considerando a primeira questão, "É possivel, por meio de dados públicos, conseguir um panorama dos cursos de Licenciatura em Computação?", entendemos que é possível usar os dados públicos para diferentes tipos de análises que permitiram apresentar uma visão geral dos cursos de Licenciatura em Computação.

Além disso, os resultados mostraram que a metodologia proposta permitiu realizar análises flexíveis e interessantes, bem como investigar proposições elencadas nas questões panorâmicas do curso Licenciatura em Computação e seus fatores de evasão. Por exemplo: o baixo número de alunos indígenas matriculados $(0,58 \%)$ e mulheres $(31,8 \%)$ e as diferenças de evasão em relação à etnia, modalidade de aprendizagem (presencial e a distância), ao tipo de cidade (capital ou não), tipo de instituição (privada ou pública), ano de entrada no curso e período do curso.

Em relação aos cursos de Licenciatura em Computação, alguns dados preocupantes são apresentados neste trabalho. Primeiramente, o número de alunos nestes cursos está diminuindo. Vale ressaltar o declínio significativo (36,3 \%) no número de ingressantes entre os censos de 2017 e 2018. Outro ponto importante é que Licenciatura em Computação apresenta a menor taxa de alunos por curso entre os da área de computação.

Com relação à segunda questão, "Quais fatores estão associados à taxa de evasão destes cursos?", pode-se destacar que o principal fator, por meio dessa análise, está no tipo de 
Instituição. As IES privadas apresentam taxas de evasão superiores às IES públicas. Além deste fator, outros fatores parecem apresentar associação com a evasão, que são:

- IES em cidade com menos de 50 mil habitantes apresentam taxas de evasão mais elevadas;

- Cursos na região Sul apresentam taxas de evasão mais elevadas;

- O número de anos que o aluno permanece no curso tem relação com a evasão;

- Alunos que entraram neste tipo de curso por alguma reserva de vaga apresentam taxas de evasão inferiores.

Também foi observado um baixo crescimento no número de cursos em Licenciatura em Computação e o aumento considerável da evasão, passando de $16,02 \%$, no censo de 2017 , para $20,81 \%$, no censo de 2018. Com relação à evasão, as IES privadas apresentam taxas de mais de $30 \%$ nos cursos. Por fim, os cursos de Licenciatura em Computação estão concentrados essencialmente em IES públicas. Apesar do aumento da taxa de evasão apresentada do censo de 2017 para 2018, nos dois anos em que os dados foram analisados os cursos de licenciatura apresentaram taxas de evasão muito próximas aos outros cursos da área de computação.

Por meio deste estudo também se percebe que o perfil dos alunos em Licenciatura em Computação apresenta diferença para os demais cursos de computação. Enquanto a idade média dos alunos de outros cursos é 24,91 anos, em licenciatura a idade média é de 30 anos. Outra diferença está no número de alunos do gênero feminino, que é mais do que o dobro da média dos outros cursos da área de computação. Por fim, $27 \%$ dos cursos em Licenciatura em Computação são na modalidade a distância, enquanto para os outros cursos da área de computação esta taxa não atinge $5 \%$.

Com relação a este estudo apontamos duas limitações: a primeira está relacionada ao escopo da análise, que considerou apenas os últimos dois anos (2017 e 2018) do censo; a segunda está associada à construção da própria base de dados do censo, uma vez que as IES informam dados ao INEP, o que pode causar uma possível falta de padrão entre os conceitos utilizados.

As futuras linhas de trabalho devem se concentrar na adaptação do processo de coleta de dados para incluir dados adicionais; de outros cursos e anos, por exemplo. Outras fontes de dados também devem ser consideradas, já que podem complementar os dados existentes e expandirem o horizonte de análise para cobrir outras questões, como módulos de cursos, notas de alunos ou até mesmo variáveis socioeconômicas. Acreditamos que isso pode gerar um grande impacto na análise de dados e fornecer informações interessantes para gerentes acadêmicos. Neste estudo os dados dos cursos de Licenciatura em Computação foram confrontados com os dados de outros cursos da área de computação apenas. Como trabalho futuro, estes dados poderiam serem confrontados com dados de outros cursos de licenciatura.

\section{Agradecimentos}

Agradecemos ao Programa de Pós-Graduação em Ensino da Universidade Estadual do Norte do Paraná por possibilitar a realização do estágio de pós-doutoramento.

\section{Referências}

ANDIFES/ABRUEM/SESu/MEC. (1996). Diplomação, Retenção e Evasão nos Cursos de Graduação em Instituições de Ensino Superior Públicas. http://www.andifes.org.br/wpcontent/files_flutter/Diplomacao_Retencao_Evasao_Graduacao_em_IES_Publicas1996.pdf. [GS Search] 
Baranauskas, M. C. C., Rocha, H. V. R., Martins, M .C., \& D’Abreu, J. V. V. Uma taxonomia para ambiente de aprendizados baseados no computador. In: Análise dos diferentes tipos de software usados na educação. In: Valente, J. A (org.) O computador na sociedade do conhecimento - Campinas, SP: UNICAMP/NIED, p. 49-88. Disponível em: https://www.nied.unicamp.br/biblioteca/o-computador-na-sociedade-do-conhecimento/. [GS $\underline{\text { Search] }}$

Barreto, D., de Matos, M., da Hora, H., \& de Vasconcelos, A. (2019). EVASÃO NO ENSINO SUPERIOR: INVESTIGAÇÃO DAS CAUSAS VIA MINERAÇÃO DE DADOS. Educação Profissional E Tecnológica Em Revista,3(2), 3-21. doi: 10.36524/profept.v3i2.432. [GS Search]

Bell, T.; Witten, I. \& Fellows, M. (2011). Computer Science Unplugged: Ensinando Ciência da Computação sem o uso do computador. 2011. Tradução coordenada por Luciano Porto Barreto. Disponível em: https://classic.csunplugged.org/wpcontent/uploads/2014/12/CSUnpluggedTeachers-portuguese-brazil-feb-2011.pdf. $\quad$ [GS $\underline{\text { Search }}$

Berardi, R., \& Bim, S. (2017). A crise de identidade dos cursos de Sistemas de Informação é percebida "além-muros" das universidades no sul do Brasil? (Is the identity crisis of Information Systems courses perceived "beyond walls" of universities in southern Brazil?). Isys: Revista Brasileira De Sistemas De Informação (Brazilian Journal Of Information Systems), 10(4), 24-44. [GS Search]

Brasil. (2015) Ministério da Educação - Conselho Nacional de Educação Conselho Pleno (org.). Resolução no. 2, de $1^{o}$ de julho de 2015. Disponível em http://portal.mec.gov.br/docman/agosto-2017-pdf/70431-res-cne-cp-002-03072015-pdf/file.

Brasil (2016). Ministério da Educação Conselho Nacional de Educação - Câmara de Educação Superior (Org.). Resolução no. 5, de 16 de novembro de 2016. Disponível em: http://portal.mec.gov.br/index.php?option $=$ com docman\&view $=$ download\&alias $=52101$ rces005-16-pdf\&category slug=novembro-2016-pdf\&Itemid $=30192$

Brasil. (2018). Ministério da Educação Conselho Nacional de Educação - Câmara de Educação Superior (Org.). Base Nacional Comum Curricular: Educação é a Base. Disponível em: http://basenacionalcomum.mec.gov.br.

Brasil (2019). Instituto Nacional de Estudos e Pesquisas Educacionais Anísio Teixeira (Inep). Censo da Educação Superior 2018. Brasília, 2019. [GS Search]

Brito, M.; Medeiros, F.; Bezerra, E \& Barbosa, A. (2020). Contribuições de um Plugin do tipo Report para a Identificação do Risco de Evasão no AVA Moodle com base em Visualização de Dados. Revista Brasileira de Informática na Educação (RBIE), 20, 1-29. doi: $\underline{10.5753 / \text { rbie.2020.28.0.01. [GS Search] }}$

Calixto, C. (2015). Análise das causas de evasão discente no curso de Licenciatura em Computação: um estudo da UFPB virtual no formato UAB. Revista Tecnologias na Educação, 7 (12), 1-13.

Costa, F.; Bispo, M. \& Pereira, R. (2018). Dropout and retention of undergraduate students in management: a study at a Brazilian Federal University. RAUSP Management Journal, 53 (1), 74-85. doi: 10.1016/j.rauspm.2017.12.007. [GS Search]

Damasceno, I. \& Carneiro, M. (2018) Panorama da Evasão no Curso de Sistemas de Informação da Universidade Federal de Uberlândia: Um Estudo Preliminar. Anais do Xxix Simpósio Brasileiro de Informática na Educação (sbie 2018), 1766-1779. Doi: $\underline{10.5753 / \text { cbie.sbie.2018.1766. [GS Search] }}$ 
Fritsch, R.; Rocha, C.; Vitelli, R. (2015). A evasão nos cursos de graduação em uma instituição de ensino superior privada. Revista Educação em Questão, 52 (38), 81-108. doi: 10.21680/1981-1802.2015v52n38id7963. [GS Search]

Gregor, S. \& Hevner, A. (2013). Positioning and Presenting Design Science Research for Maximum Impact. Mis Quarterly, 37 (2), 337-355. doi: 10.25300/misq/2013/37.2.01. [GS Search]

Hoffmann, I. L., Nunes, R. C., \& Muller, F. M. (2019). The information of a Higher Education Census in the implementation of organizational knowledge management on school dropout. Gestão \& Produção, 26(2), e2852. doi:10.1590/0104-530X-2852-19. [GS Search]

Lassibille, G. \& Gómez, L. (2008). Why do higher education students drop out? Evidence from Spain. Education Economics, 16(1), 89-105. doi: 10.1080/09645290701523267. [GS Search]

Lobo, M. (2006). Instituto Lobo para Desenvolvimento da Educação, da Ciência e da Tecnologia. Panorama Da Evasão No Ensino Superior Brasileiro: Aspectos Gerais Das Causas E Soluções. Disponível em: https://www.institutolobo.org.br/imagens/pdf/artigos/art 087.pdf. [GS Search]

Peffers, K., Tuunanen, T., Rothenberger, M., \& Chatterjee, S. (2007). A Design Science Research Methodology for Information Systems Research. Journal Of Management Information Systems, 24(3), 45-77. doi: 10.2753/mis0742-1222240302. [GS Search]

Prietche, S. \& Pazeto, T. (2010). Estudo sobre a evasão em um curso de licenciatura em informática e considerações para melhorias. In: Workshop De Educação Em Informática, Anais do VIII do Workshop em Educação em Informática (WEIBASE). Maceió/AL. [GS Search]

Rodrigues, F.; Brackmann, C. \& Barone, D. (2015). Estudo Da Evasão No Curso De Ciência Da Computação Da Ufrgs. Revista Brasileira de Informática na Educação, 23(01), 97-104. doi: 10.5753/rbie.2015.23.01.97. [GS Search]

Saccaro, A., França, M., \& Jacinto, P. (2019). Fatores Associados à Evasão no Ensino Superior Brasileiro: um estudo de análise de sobrevivência para os cursos das áreas de Ciência, Matemática e Computação e de Engenharia, Produção e Construção em instituições públicas e privadas. Estudos Econômicos (São Paulo), 49(2), 337-373. doi: 10.1590/010141614925amp. [GS Search]

Saraiva, J., Dantas, V., \& Rodrigues, A. (2019). Compreendendo a Evasão em uma Década no Curso Sistemas de Informação à luz de fatores humanos e sociais. Anais Do Workshop Sobre Aspectos Sociais, Humanos E Econômicos De Software (WASHES). doi: 10.5753/washes.2019.6406. [GS Search]

SBC. (2014). Sociedade Brasileira de Computação. Educação Superior em Computação Estatísticas - 2014. Disponível em: https://www.sbc.org.br/documentos-da-sbc/send/133estatisticas/1007-estatisticas-da-educacao-superior-2014.

Silva Filho, P.; Hipólito, O. \& Lobo, M (2007). A evasão no ensino superior brasileiro. Cadernos de pesquisa, 37 (132), 641-659. [GS Search]

Slhessarenko, M., Gonçalo, C., Beira, J., \& Cembranel, P. (2014). A evasão na educação superior para o curso de bacharelado em sistema de informação. Revista Gestão Universitária Na América Latina - GUAL, 7(1), 128. doi: 10.5007/1983-4535.2014v7n1p128. [GS Search]

Song Y., Rowen, W., Medsker, C., \& Ewen, E. (2001). An Analysis of Many-to-Many Relatioships Between Fact and Dimension Tabels in Dimensional Modeling. In: Proceedings 
of International Workshop on Design and Management of Data Warehouses (DMDW'01), Zurich, Switzerland. [GS Search]

Valente, J. A. (1999a). Informática na Educação no Brasil: análise e contextualização histórica. In: In: Valente, J. A (org.) O computador na sociedade do conhecimento - Campinas, SP: UNICAMP/NIED, p. 1-28. Disponível em: https://www.nied.unicamp.br/biblioteca/ocomputador-na-sociedade-do-conhecimento/. [GS Search]

Valente, J. A. (1999b). Análise dos diferentes tipos de software usados na educação. In: Valente, J. A (org.) O computador na sociedade do conhecimento - Campinas, SP: UNICAMP/NIED, p. 89-99. Disponível em: https://www.nied.unicamp.br/biblioteca/o-computador-nasociedade-do-conhecimento/. [GS Search]

Vasconcelos, V. \& Andrade, E. (2018). Análise da Evasão de Alunos na Licenciatura em Computação. In: Anais do XXVI Workshop sobre Educação em Computação. Porto Alegre. [GS Search]

Yin, R. (2013). Case Study Research: Design and Methods. (5. Ed). Sage Publications. [GS Search]

Zorzo, F.; Matos, E.; Steinmacher, I.; Leite, J.; Araujo, R.; Correia, R. \&, S. (2017) Referenciais de Formação para os Cursos de Graduação em Computação. Sociedade Brasileira de Computação (SBC). 153p, ISBN 978-85-7669-424-3. [GS Search] 